Federal Reserve Bank of Dallas

Globalization and Monetary Policy Institute

Working Paper No. 84

http://www.dallasfed.org/assets/documents/institute/wpapers/2011/0084.pdf

\title{
Sharing the Burden: Monetary and Fiscal Responses to a World Liquidity Trap*
}

\author{
David Cook \\ Hong Kong University of Science and Technology \\ Michael B. Devereux \\ University of British Columbia
}

June 2011

\begin{abstract}
With integrated trade and financial markets, a collapse in aggregate demand in a large country can cause 'natural real interest rates' to fall below zero in all countries, giving rise to a global 'liquidity trap'. This paper explores the optimal policy response to this type of shock, when governments cooperate on both fiscal and monetary policy. Adjusting to a large negative demand shock requires raising world aggregate demand, as well as redirecting demand towards the source (home) country. The key feature of demand shocks in a liquidity trap is that relative prices respond perversely. A negative shock causes an appreciation of the home terms of trade, exacerbating the slump in the home country. At the zero bound, the home country cannot counter this shock. Because of this, it may be optimal for the foreign policy-maker to raise interest rates. Strikingly, the foreign country may choose to have a positive policy interest rate, even though its 'natural real interest rate' is below zero. A combination of relatively tight monetary policy in the foreign country combined with substantial fiscal expansion in the home country achieves the desired mix in terms of the level and composition of world expenditure. Thus, in response to conditions generating a global liquidity trap, there is a critical mutual interaction between monetary and fiscal policy.
\end{abstract}

JEL codes: E2, E5, E6

\footnotetext{
* David Cook, Hong Kong University of Science and Technology, Department of Economics, Clearwater Bay, Kowloon, Hong Kong SAR, China. 852-2358-7614. davcook@ust.hk. Michael B. Devereux, Department of Economics, University of British Columbia, 997-1873 East Mall, Vancouver, BC, V6T $1 Z 1$. 604-822-2542. mbdevereux@gmai.com. We thank seminar participants at the Bank of Japan, participants of the ECB-Bundesbank workshop, the Bundesbank Spring Conference 2011, Paul Beaudry, Nao Sudou, Ippei Fujiwara, Takahashi Ito, and Gernot Muller for comments. The views in this paper are those of the authors and do not necessarily reflect the views of the Federal Reserve Bank of Dallas or the Federal Reserve System.
} 


\section{Introduction}

This paper is concerned with global policy responses to a world liquidity trap. The macroeconomic situation of the world economy was profoundly altered by the experience of the Great Recession that began in 2008. By general consensus, the source of the shock was the US financial sector, but this subsequently led to a fall in world aggregate demand, spilling over to the economies of many other countries. How should policymakers respond when aggregate demand shocks push world 'natural real interest rates' below zero? As is well known (e.g. Eggertson and Woodford 2003), when desired real interest rates are below zero, there is a failure of the 'divine coincidence' that monetary policy can simultaneously deliver zero inflation and a zero output gap. Of course, even when policy interest rates are at a lower bound, monetary policy may still be effective through an expectations channel, but the effectiveness of announcements about future monetary policy is questionable, given the implausibility of 'committing to be irresponsible' in the future (Krugman 1998). An alternative is to use fiscal policy. In the aftermath of the crisis, many countries followed significant expansions in government deficits, reducing taxes and/or increasing government spending. At the beginning of the downturn, there was a concerted effort to coordinate these fiscal expansion across countries, through the G20 process and other venues. But the ensuing fiscal responses were far from uniform across different countries. In addition, some countries have already begun to raise policy rates, while in the US, interest rates remain effectively at their zero bound.

A key question is how the 'burden of adjustment' to a global recession should be shared across countries that experience the downturn at different levels of severity.This specific focus of the paper is to identify an optimal policy response to a world liquidity trap in which two trading partners are well integrated through financial markets but less than perfectly integrated in goods markets. We think of an aggregate demand shock as coming from one country, but spilling over into other countries by pushing down desired real interest rates below zero in all countries. A policy response in our model is a joint monetary-fiscal package, and we focus on cooperative policies. We emphasize that a liquidity trap is not a mechanical occurance, but a decision to reduce policy rates to zero when the natural real interest rate goes below zero. In this respect, the international dimension to macroeconomic policy at the zero lower bound introduces some intriguing complications. The particular complicating feature is the degree of trade integration. With highly open trade linkages, the optimal policy response closely mirrors that of a closed economy. Policy interest rates are set at zero, and both economies should follow similarly expansionary fiscal packages. The 
reason is that when international trade is highly integrated, a demand slump in one country is felt equally in all other countries, via interconnected goods and financial markets. Output and inflation in all countries will respond symmetrically to demand shocks, regardless of the source of the shock, and the optimal policy response is to have interest rates as low as possible, and an equal fiscal expansion in all countries.

However, the benchmark of fully open trade does not closely approximate the current configuration of the world economy, where large, but relatively closed economies, such as Japan and the United States, are stuck in a liquidity trap. In these countries, exports make up substantially less than $20 \%$ of GDP. With home bias in consumption baskets, which acts so as to reduce trade linkages between countries, both the propagation of demand shocks and the optimal response of policy to shocks takes on very different characteristics. Typically, a large negative demand shock in one country will push down the desired real interest rate in that country more than those of its trading partners. Moreoever, the introduction of home bias complicates the analysis of optimal policy, since the international effects of a demand shock on output and inflation are not distributed equally across countries.

The key feature of the environment with home bias in trade is that a shock that precipitates a liquidity trap generates a perverse response of the terms of trade. Under 'normal' monetary policy, a fall in demand will reduce domestic real interest rates and lead to a compensating terms of trade deterioration, channelling more world demand towards the country directly affected by the shock. But when the interest rate is at the zero bound, this same shock generates a terms of trade appreciation, since it tends to raise domestic real interest rates by pushing down inflation expectations. Hence, the response of the terms of trade exacerbates the effect of the shock. Typically, in order to alleviate a terms of trade appreciation, a country could engage in expansionary monetary policy. But when interest rates are zero, the home country (which is the source of the shock) cannot do this. But instead, the foreign country can raise its interest rate. We find in fact that an optimal cooperative response involves a large fiscal expansion in the home country, and a positive interest rate for the foreign country, in conjunction with a small fiscal expansion. That is, the least hit (foreign) economy should only minimally engage in a cooperative fiscal expansion, but should set its policy rate above its natural real interest rate. Strikingly, we find that the best policy (from a global cooperative perspective), is for the foreign country to tighten monetary policy, even though using the standard criterion from the closed economy logic, it should still be in a liquidity trap (where its 'natural' real interest rate is below zero). The foreign interest rate increase acts so as weaken the appreciation of the home terms of trade caused by the original demand shock, limiting the degree of world expenditure switching away from 
the home economy. Overall, it is best for both countries to have higher interest rates in the trading partner, when the source country shock requires zero home interest rates.

Our results in fact show that the response of policy interest rates in a global liquidity trap are piecewise functions of the degree of trade-openness, as measure by the parameter of 'home bias' in preferences. When preferences are identical, trade is fully open, and a global liquidity trap is associated with zero policy rates in all countries. For a shock coming from the home country, home policy rates are always set equal to zero. As preferences display more home bias, both policy rates are still zero for some interval. But at a critical threshold level of home bias, foreign interest rates are raised, even when the foreign natural real interest rate is negative. As the degree of home bias rises, foreign policy rates rise more and more, and are always set above the foreign natural real interest rate.

The message is that the open economy dimension has very substantial implications for both the occurrance of a liquidity trap, in the sense that it predicts that policy is not restricted by the zero lower bound even when traditional indicators (which look at the value of the 'natural real interest rate') say that it should be, and for the way in which policy is designed when the world economy 'on average' is in a liquidity trap. More generally, the model predicts that the 'burden of adjustment' to a global liquidity trap may be spread quite unequally across countries, and implies some apparently counterintuitive policy responses.

An alternative perspective on the results is that they show how monetary and fiscal policy should be used in a mutually supportive way in responding to a global liquidity trap shock. If monetary policy were set in a conventional way, so that policy rates were equal to natural real interest rates, except when the latter variables were below zero, then all the burden of adjustment would be on fiscal policy. In this case, in order to facilitate expenditure adjustment and expenditure switching, a policy response would require a large home fiscal expansion and foreign fiscal contraction. The reason is that fiscal expansion in a liquidity trap generates terms of trade depreciation - (Cook and Devereux, 2011). The benefit of adjusting foreign interest rates optimally is that it relieves (but does not eliminate) the need for large fiscal responses in each country.

The paper builds on a substantial recent literature on monetary and fiscal policy in a liquidity trap. In particular, with the experience of Japan in mind Krugman (1999), Eggertson and Woodford (2003, 2005), Jung et al. (2005), Svensson (2003), Auerbach and Obstfeld (2004) and many other writers explored how monetary and fiscal policy could be usefully employed even when the authorities have no further room to reduce short term nominal interest rates. Recently, a number of authors have revived this literature in light of the very similar problems now encountered by the economies of Western Europe and North 
America. Papers by Christiano et al (2009), Devereux (2010), Eggertson (2009), Taylor et al. (2008) have explored the possibility for using government spending expansions, tax cuts, and monetary policy when the economy is in a liquidity trap. For the most part, these papers did not focus on the international dimension of liquidity traps. Some recent expections are Fujiwara et al. (2009, 2010), Erceg et al. (2009) and Jeanne (2009). Jeanne (2009) examines a 'global liquidity trap' in a model of one-period ahead pricing similar to that of Krugman (2009). Erceg. et al (2009) use a fully specific two country DSGE model to examine the international transmission of shocks when one country is in a liquidity trap, but do not focus on optimal monetary policy or fiscal policy choices. Fujiwara et al. (2009) examine the optimal monetary problem with commitment in a multi country situation, but do not examine the determination of fiscal policy, or the transmission of demand shocks across countries. Fujiwara et al. (2010) look at the impact of the international effects of fiscal policy in a liquidity trap, examing the sign and size of domestic and international fiscal multipliers. Our paper may be seen as complementary to theirs in that we extend the analysis to incorporate trade frictions, but more importantaly, investigate the determination of optimal policy ${ }^{1}$.

The rest of the paper is organized as follows. The next section develops the basic model. Section 3 examines the solution under sticky prices. Then in section 4 we analyze the impact of fiscal policies at the zero lower bound, and the role of international spillovers of policies. Section 5 examines the optimal policy making problem in a global cooperative agreement, including the possibility of using both monetary and fiscal policy for the least affected countries. Some conclusions are then offered.

\section{A two country model of interacting monetary and fiscal policy}

We construct a model in which there are two countries in the world economy. In each country, households consume both private and government goods, and supply labor. Denote the countries as 'home' and 'foreign', with foreign variables denoted with an asterisk superscript. The population of each country is normalized to unity. Each country produces a range of differentiated goods. Complete asset markets allow full insurance of consumption risk across countries. Households also hold their own country's nominal government bonds. Firms

\footnotetext{
${ }^{1}$ In addition, a previous paper (Cook and Devereux, 2011) examines the linkages of natural real interest rates, the determination of fiscal multipliers and optimal fiscal policy in a simpler version of the model of the present paper, but does not allow for the endogenous response of monetary policy.
} 
produce private goods, while governments produce government goods which are distributed uniformly across households. Firms production and supply is constrained by sticky prices. Governments have access to lump sum taxation.

\subsection{Households}

Utility of a representative infinitely lived home household evaluated from date 0 is:

$$
U_{t}=E_{0} \sum_{t=0}^{\infty}(\beta)^{t}\left(U\left(C_{t}, \xi_{t}\right)-V\left(N_{t}\right)+J\left(G_{t}\right)\right)
$$

where $U, V$, and $J$ represent the utility of the composite home consumption bundle $C_{t}$, disutility of labour supply $N_{t}$, and utility of the government supplied public good $G_{t}$, respectively. The variable $\xi_{t}$ represents a shock to preferences or 'demand'. We assume that $U_{12}>0$..

Composite consumption is defined as

$$
C_{t}=\Phi C_{H t}^{v / 2} C_{F t}^{1-v / 2}, \quad v \geq 1
$$

where $\Phi=\left(\frac{v}{2}\right)^{\frac{v}{2}}\left(1-\left(\frac{v}{2}\right)\right)^{\frac{v}{2}}, C_{H}$ is the consumption of the home country composite good by the home household, and $C_{F}$ is consumption of the foreign composite good. If $v>1$ then there is a home preference bias for domestic goods. The case $v>1$ is most realistic for thinking about policy in large open economies.

Consumption aggregates, $C_{H}$ and $C_{F}$ are composites, defined over a range of home and foreign differentiated goods, with elasticity of substitution $\theta$ between goods, so that:

$$
C_{H}=\left[\int_{0}^{1} C_{H}(i)^{1-\frac{1}{\theta}} d i\right]^{\frac{1}{1-\frac{1}{\theta}}}, \quad C_{F}=\left[\int_{0}^{1} C_{F}(i)^{1-\frac{1}{\theta}} d i\right]^{\frac{1}{1-\frac{1}{\theta}}}, \quad \theta>1 .
$$

Price indices for home and foreign consumption are:

$$
P_{H}=\left[\int_{0}^{1} P_{H}(i)^{1-\theta} d i\right]^{\frac{1}{1-\theta}}, \quad P_{F}=\left[\int_{0}^{1} P_{F}(i)^{1-\theta} d i\right]^{\frac{1}{1-\theta}}
$$

while the aggregate (CPI) price index for the home country is $P=P_{H}^{v / 2} P_{F}^{1-v / 2}$ and for the foreign is $P_{t}^{*}=P_{F}^{* v / 2} P_{H}^{* 1-v / 2}$

Demand for each differentiated $\operatorname{good}(j=H, F)$ is

$$
\frac{C_{j}(i)}{C_{j}}=\left(\frac{P_{j}(i)}{P_{j}}\right)^{-\theta}
$$


The law of one price holds for each good so $P_{j}(i)=S P_{j}^{*}(i)$.where $S_{t}$ is the nominal exchange rate (home price of foreign currency). Relative demand for the composites is:

$$
\frac{C_{H}}{C_{F}}=\frac{P_{F}}{P_{H}}=\frac{S P_{F}^{*}}{P_{H}}
$$

Home government spending falls on the home composite good and foreign government spending on the foreign composite good. Thus, government spending is assumed to have full 'home bias'. In addition, we assume that government spending demand for each variety of home goods has price elasticity $\theta$, the same as that for private spending.

The household's implicit labor supply at nominal wage $W_{t}$ is:

$$
U_{C}\left(C_{t}, \xi_{t}\right) W_{t}=P_{t} V^{\prime}\left(N_{t}\right)
$$

Optimal risk sharing implies

$$
U_{C}\left(C_{t}, \xi_{t}\right)=U_{C}\left(C_{t}^{*}, \xi_{t}^{*}\right) \frac{S_{t} P_{t}^{*}}{P_{t}}=U_{C}\left(C_{t}^{*}, \xi_{t}^{*}\right) T_{t}^{v-1},
$$

Nominal bonds pay interest, $R_{t}$. Then the Euler equation is:

$$
\frac{U_{C}\left(C_{t}, \xi_{t}\right)}{P_{t}}=\beta R_{t} E_{t} \frac{U_{C}\left(C_{t+1}, \xi_{t+1}\right)}{P_{t+1}} .
$$

Foreign household preferences and choices can be defined exactly symmetrically. The foreign representative household has weight $v / 2,(1-v / 2)$ on the foreign (home) compositive good in preferences.

\section{$2.2 \quad$ Firms}

Each firm $i$ employs labor to produce a differentiated good.

$$
Y_{t}(i)=N_{t}(i)
$$

Profits are $\Pi_{t}(i)=P_{H t}(i) Y_{t}(i)-W_{t} H_{t}(i) \frac{\theta-1}{\theta}$ indicating a subsidy financed by lump-sum taxation to eliminate steady state first order inefficiencies. Each firm re-sets its price according to Calvo pricing with probability of adjusting prices equal to $1-\kappa$. Firms that adjust their price set new price given by $\widetilde{P}_{H t}(i)$ :

$$
\widetilde{P}_{H t}(i)=\frac{E_{t} \sum_{j=0} m_{t+j} \kappa^{j} \frac{W_{t+j}}{A_{t+j}} Y_{t+j}(i)}{E_{t} \sum_{j=0} m_{t+j} \kappa^{j} Y_{t+j}(i)} .
$$


where stochastic discount factor $m_{t+j}=\frac{P_{t}}{U_{C}\left(C_{t}, \varepsilon_{t}\right)} \frac{U_{C}\left(C_{t+j}, \xi_{t+j}\right)}{P_{t+j}}$. In the aggregate, the price index for the home good then follows the process given by:

$$
P_{H t}=\left[(1-\kappa) \widetilde{P}_{H t}^{1-\theta}+\kappa P_{H t-1}^{1-\theta}\right]^{\frac{1}{1-\theta}} .
$$

The behaviour of foreign firms and the foreign good price index may be described analogously.

\subsection{Market Clearing}

Equilibrium in the market for good $i$ as

$$
Y_{H t}(i)=\left(\frac{P_{H t}(i)}{P_{H t}}\right)^{-\theta}\left[\frac{v}{2} \frac{P_{t}}{P_{H t}} C_{t}+\left(1-\frac{v}{2}\right) \frac{S_{t} P_{t}^{*}}{P_{H t}} C_{t}^{*}+G_{t}\right],
$$

where $G_{t}$ represents total home government spending. Aggregate market clearing in the home good is:

$$
Y_{H t}=\frac{v}{2} \frac{P_{t}}{P_{H t}} C_{t}+\left(1-\frac{v}{2}\right) \frac{S_{t} P_{t}^{*}}{P_{H t}} C_{t}^{*}+G_{t} .
$$

Here $Y_{H t}=V_{t}^{-1} \int_{0}^{1} Y_{H t}(i) d i$ is aggregate home country output, where we have defined $V_{t}=\int_{0}^{1}\left(\frac{P_{H t}(i)}{P_{H t}}\right)^{-\theta} d i$. It follows that home country employment (employment for the representative home household) is given by $N_{t}=\int_{0}^{1} N(i) d i=Y_{H t} V_{t}$.

The aggregate market clearing condition for the foreign good is

$$
Y_{F t}=\frac{v}{2} \frac{P_{t}^{*}}{P_{F t}^{*}} C_{t}^{*}+\left(1-\frac{v}{2}\right) \frac{P_{t}}{S_{t} P_{F t}^{*}} C_{t}^{*}+G_{t}^{*},
$$

where: $N_{t}^{*}=\int_{0}^{1} N_{t}^{*}(i) d i=Y_{F t} V_{t}^{*}$, where $V_{t}^{*}=\int_{0}^{1}\left(\frac{P_{F t}^{*}(i)}{P_{F t}^{*}}\right)^{-\theta} d i$.

An equilibrium in the world economy with positive nominal interest rates may be described by the equations (3), and (2), (4), (5) and (6) for the home and foreign economy, as well as (7) and (8). For given values of $V_{t}$ and $V_{t}^{*}$, given monetary rules (to be discussed below) and given government spending policies, these equations determine an equilibrium sequence for the variables $C_{t}, C_{t}^{*}, W_{t}, W_{t}^{*}, S_{t}, P_{H t}, P_{F t}^{*}, \widetilde{P}_{H t}, \widetilde{P}_{F t}^{*}, R_{t}, R_{t}^{*}$, and $N_{t}, N_{t}^{*}$. 


\section{New Keynesian Open Economy Model}

\subsection{Demand Shocks and Natural Interest Rates}

Define $\sigma \equiv-\frac{U_{C C} \bar{C}}{U_{C}}$ as the inverse of the elasticity of intertemporal substitution in consumption, $\phi \equiv-\frac{V^{\prime \prime} \bar{H}}{V^{\prime}}$ as the elasticity of the marginal disutility of hours worked and $\sigma_{g} \equiv-\frac{J^{\prime \prime} \bar{G}}{J^{\prime}}$ as the elasticity of marginal utility of public goods. In addition, we assume that $\sigma_{g}=\sigma>1$. Finally, $\varepsilon_{t}=\frac{U_{C \xi}}{U_{C}} \ln \left(\xi_{t}\right)$ is the measure of a positive demand shock in the home country, with an equivalent definition for the foreign country. Define $c_{y}=\frac{C}{Y}$ is the steady state share of consumption in output.

We assume that any preference shock is unanticipated, and reverts back to zero with probability $1-\mu$ in each period. Because there are no predetermined state variables in the model, this implies that all variables in the world economy will inherit the same persistence as the shock itself, in expectation. Thus, for any variable $x_{t}$, we may write $E_{t}\left(x_{t+1}\right)=\mu x_{t}$. After the shock expires, all variables will then revert to their zero initial equilibrium.

We first derive a measure of Wicksellian, or 'natural' real interest rates for each country, defined as the interest rates that would hold in a purely flexible price equilibrium of the world economy where there are no monopolistic distortions, and in addition where governments choose an optimal fiscal spending rule with access to lump-sum taxes. In this case, the government spending rate for the home economy will be determined by:

$$
V^{\prime}\left(N_{t}\right)=J^{\prime}\left(G_{t}\right)
$$

For any variable $x_{t}$, define the world average and world relative level, $x_{t}^{W}=\frac{x_{t}+x_{t}^{*}}{2}$ and $x_{t}^{R}=$ $\frac{x_{t}-x_{t}^{*}}{2}$. In a competitive equilibrium with optimal government spending in both countries as in (9), the natural real interest rate of the home and foreign economy are defined as: ${ }^{2}$.

$$
\begin{aligned}
& \widetilde{r}_{t}=\bar{r}+\left(\frac{\phi c_{y}}{\phi+\sigma} \varepsilon_{t}^{W}+\frac{\phi c_{y}(v-1)}{\Delta} \varepsilon_{t}^{R}\right)(1-\mu) \\
& \widetilde{r}_{t}^{*}=\bar{r}+\left(\frac{\phi c_{y}}{\phi+\sigma} \varepsilon_{t}^{W}-\frac{\phi c_{y}(v-1)}{\Delta} \varepsilon_{t}^{R}\right)(1-\mu)
\end{aligned}
$$

where $\Delta \equiv \phi c_{y} D+\phi\left(1-c_{y}\right)+\sigma$ and $\sigma>D \equiv\left(\sigma v(2-v)+(1-v)^{2}\right)>1$. These are critical variables for our analysis, since they govern the degree to which monetary policy can be efficiently employed to stabilize the economy. In particular, our model has the characteristic that when (10) and (11) are both positive, then monetary policy can perfectly

\footnotetext{
${ }^{2}$ Note that this is defined as the value of $r_{t}-E_{t} \pi_{H t+1}$ in a flexible price economy, or in other words, the PPI based real interest that would hold with flexible prices.
} 
achieve the joint target of zero inflation and zero output gaps, since home and foreign policy rates can simply be set to equal (10) and (11), respectively. In addition, as seen below, there will then be no need to have fiscal gaps differ from zero.

Note that in the no home bias case, when $v=1$, the natural interest rate for both economies should be the same, so that $\widetilde{r}_{t}=\widetilde{r}_{t}^{*}=\bar{r}+\left(\frac{\phi c_{y}}{\phi+\sigma} \varepsilon_{t}^{W}\right)(1-\mu)$. The reason is that, with no home bias, demand shocks have no effect on the terms of trade. As a result, with financial market integration, PPI based real interest rates are equalized across countries. But in fact, the case $v=1$ is not particularly realistic. For most economies, and particularly for large open economies, the lion's share of demand will come from the domestic economy, making the home bias case most relevant. We will therefore focus on the more general case where $v>1$.

For concreteness, we also look at the case where the home country is the source of the shocks. In particular, we will assume that home consumers are affected by preference shocks which affect their propensity to save, whereas consumers in the foreign economy is not directly affected by these shocks. Of course foreign consumers will be indirectly affected by the shock, since integrated financial markets lead to linkages between interest rates. Thus, a saving shock with its source in the home economy, pushing the monetary authority into a liquidity trap, may have similar effects on the foreign economy, even though the foreign consumers are not directly affected by the shock.

Making this assumption, we have in this case, $\varepsilon_{t}^{*}=0$ and $\varepsilon_{t}^{W}=\varepsilon_{t}^{R}=\frac{\varepsilon_{t}}{2}$ and we can write the natural real interest rates as:

$$
\begin{aligned}
& \widetilde{r}_{t}=\bar{r}+\left(\frac{\Delta+(\phi+\sigma)(v-1)}{(\phi+\sigma) \Delta}\right)(1-\mu) \phi c_{y} \frac{\varepsilon_{t}}{2} \\
& \widetilde{r}_{t}^{*}=\bar{r}+\left(\frac{\Delta-(\phi+\sigma)(v-1)}{(\phi+\sigma) \Delta}\right)(1-\mu) \phi c_{y} \frac{\varepsilon_{t}}{2}
\end{aligned}
$$

We may rewrite the natural real interest rate expressions in shorthand as $\tilde{r}\left(\varepsilon_{t}, v\right)$ and $\tilde{r}^{*}\left(\varepsilon_{t}, v\right)$. If the home country shock is sufficiently negative, then it may drive natural real interest rates below zero. We define $\varepsilon_{H}(v)$ and $\varepsilon_{F}(v)$ respectively as the size of the shock such that $\tilde{r}\left(\varepsilon_{H}, v\right)=0$, and $\tilde{r}^{*}\left(\varepsilon_{F}, v\right)=0$. Clearly, for $v \geq 1, \varepsilon_{H} \geq \varepsilon_{F}$. Figure 1 illustrates the two functions $\tilde{r}\left(\varepsilon_{t}, v\right)$ and $\tilde{r}^{*}\left(\varepsilon_{t}, v\right)$. For $v=1$, they coincide, while for $v=2$, the foreign natural real interest rate is simply $\bar{r}$. As the countries move from being more open to more closed, the impact of the shock on the home country natural real interest rate rises, while the impact on the foreign natural real interest rate falls.

In the discussion below, we will focus on a 'large' shock, such that $\varepsilon_{t}<\varepsilon_{H}(1)$. This 
means that whatever is $v$, the home country natural real interest rate is always below zero.

\subsection{The World and Relative Economy}

We derive a sticky price log-linear approximation of the model in terms of inflation and output gaps in a similar manner to Clarida et al. (2002) and Engel (2010). Let $\widehat{x}_{t}$ be the percentage deviation of a given variable $x_{t}$ from the efficient zero flexible price equilibrium. Thus, $\widehat{x}_{t}$ is interpreted as a 'gap' variable. As defined before, $D \equiv \sigma v(2-v)+(1-v)^{2}>1$. In addition, let $s \equiv \frac{\sigma}{c_{y}}$, and $s>s_{D} \equiv \frac{s}{D}>1$.

In order to explore the implications of the zero lower bound constraint, we begin with the standard forward looking inflation equations and open economy IS relationships, expressed in terms of world averages and world relatives. The world average equations are:

$$
\begin{gathered}
\pi_{t}^{W}=k(\phi+s) \widehat{n}_{t}^{W}-k s \cdot \widehat{c g}_{t}^{W}+\beta E_{t} \pi_{t+1}^{W} \\
s E_{t}\left(\widehat{n}_{t+1}^{W}-\widehat{n}_{t}^{W}\right)-s E_{t}\left(\widehat{c g}_{t+1}^{W}-\widehat{c g}_{t}^{W}\right)=E_{t}\left(r_{t}^{W}-\widehat{r}_{t}^{W}-\pi_{t+1}^{W}\right)
\end{gathered}
$$

The world 'relative' variables are written as:

$$
\begin{gathered}
\pi_{t}^{R}=k\left(\phi+s_{D}\right) \widehat{n}_{t}^{R}-k s_{D} \widehat{c g}_{t}^{R}+\beta E_{t} \pi_{t+1}^{R} \\
s_{D} E_{t}\left(\widehat{n}_{t+1}^{R}-\widehat{n}_{t}^{R}\right)-s_{D} E_{t}\left(\widehat{c g}_{t+1}^{R}-\widehat{c g}_{t}^{R}\right)=E_{t}\left(r_{t}^{R}-\widetilde{r}_{t}^{R}-\pi_{t+1}^{R}\right)
\end{gathered}
$$

where $\widehat{c g}_{t}^{W} \equiv\left(1-c_{y}\right) \widehat{g}_{t}^{W}$ and $\widehat{c g}_{t}^{R} \equiv\left(1-c_{y}\right) \widehat{g}_{t}^{R}$. The coefficient $k$ depends on the degree of price rigidity. Note that, approximated around the steady state, $\widehat{n}_{t} \approx \widehat{y}_{t}, \widehat{n}_{t}^{*} \approx \widehat{y}_{t}^{*}$, so the labor gap for each country will stand in for the output gap.

If the natural interest rates of both economies are always above zero, then the monetary and fiscal authorities can achieve perfect price and output stability by setting the nominal interest rate equal to the natural real interest rate and keeping the fiscal gaps, $\widehat{g}_{t}^{W}$ and $\widehat{g}_{t}^{R}$ equal to zero. However, if one or both countries have a natural real interest rate below zero then this cannot occur, because then the world and relative policy interest rates cannot be set to equal world and relative natural rates without at least one policy rate being below zero.

Note that both systems of equations (for the world average and the world relative economies) are in the canonical form of the New Keynesian closed economy equations. The only difference comes in the parameterization of the inverse elasticity of consumption: $s$, in the case of the average economy; and, $s_{D}$, in the case of the relative world economy. Note 
that $s_{D}<s$, so the world average level of demand is less sensitive to the average interest rate than the relative level of demand is sensitive to the relative interest rate. This reflects the expenditure switching effect of terms of trade changes. When worldwide interest rates are relatively low, then (for intertemporal substitution reasons) world demand will be relatively high. Analogously, when the relative interest rate is low, demand will be relatively high in the low interest rate country. But in addition, in order to satisfy interest rate parity, a relatively low real interest rate country must have an anticipated terms of trade appreciation. This implies a current terms of trade depreciation, leading world aggregate demand to move towards the low interest rate country through the expenditure switching channel.

\section{Global Liquidity Traps}

If saving shocks are sufficiently small (i.e. so that $\varepsilon_{t}>\varepsilon_{H}(v)$, then policy rates can adjust to eliminate the effects of shocks, so that all gaps are zero. For comparison purposes however, we briefly illustrate the impact of a small shock that satisfies $\varepsilon_{t}>\varepsilon_{H}(v)$, but where instead of adjusting policy rates to offset the shocks, the monetary policy in each country follows a simple Taylor rule. This comparison is revealing to the extent that it provides a contrast to the effect of shocks when interest rates are constrained by the zero lower bound.

\subsection{Demand Shocks under a Taylor rule}

The movement of natural real interest rates is as in (10) and (11). But assume that, instead of offsetting the movement in natural real interest rates, policy interest rates are set such that:

$$
r_{t}=\bar{r}+\gamma \pi_{H t}, \quad r_{t}^{*}=\bar{r}+\gamma \pi_{F t}
$$

Using (18) in the solutions for world and relative output gaps, gives us:

$$
\begin{aligned}
\Delta_{1} \widehat{n}_{t}^{W} & =(1-\beta \mu)\left(\bar{r}-\widetilde{r}_{t}^{W}\right) \\
\Delta_{1}^{D} \widehat{n}_{t}^{R} & =(1-\beta \mu) \widetilde{r}_{t}^{R}
\end{aligned}
$$

where $\Delta_{1} \equiv s(1-\beta \mu)(1-\mu)+(\gamma-\mu) k(\phi+s)>0$, and $\Delta_{1}^{D}=s_{D}(1-\beta \mu)(1-\mu)+(\gamma-$ $\mu) k\left(\phi+s_{D}\right)>0$, with $\Delta_{1}>\Delta_{1}^{D}$.

A demand shock in the home country ensures that $\bar{r}-\widetilde{r}_{t}^{W}>0$ and $\widetilde{r}_{t}^{R}<0$. Thus, both $\widehat{n}_{t}^{W}$ and $\widehat{n}_{t}^{R}$ fall. The home and foreign output gaps are written respectively as $\widehat{n}_{t}=\widehat{n}_{t}^{W}+\widehat{n}_{t}^{R}$, and $\widehat{n}_{t}^{*}=\widehat{n}_{t}^{W}-\widehat{n}_{t}^{R}$. Thus: 


$$
\begin{aligned}
& \widehat{n}_{t}=(1-\beta \mu)\left[\frac{-\left(\bar{r}-\widetilde{r}_{t}^{W}\right)}{\Delta_{1}}+\frac{\widetilde{r}_{t}^{R}}{\Delta_{1}^{D}}\right] \\
& \widehat{n}_{t}^{*}=(1-\beta \mu)\left[\frac{-\left(\bar{r}-\widetilde{r}_{t}^{W}\right)}{\Delta_{1}}-\frac{\widetilde{r}_{t}^{R}}{\Delta_{1}^{D}}\right]
\end{aligned}
$$

The home output gap falls. The response of the foreign output gap is ambiguous, however, and depends upon both the strength of the shock as well as the openness of total trade. When $v=1, \widetilde{r}_{t}^{R}=0$, and home and foreign output gaps fall by equal amounts. Note that the first term inside the square brackets in each equation is independent of $v$. Then as $v$ rises above unity, $\widetilde{r}_{t}^{R}$ falls, $\Delta_{1}^{D}$ rises, so that the foreign output gap responds by less, and the home output gap by more.

The negative demand shock always reduces home country inflation. Foreign inflation is defined as $\pi_{t}^{W}-\pi_{t}^{R}$, which may be written as:

$$
\pi_{t}^{*} \propto k(\phi+s) \widehat{n}_{t}^{*}+k\left(s-s_{D}\right) \widehat{n}_{t}^{R}
$$

A sufficient condition for foreign inflation to fall is that the foreign output gap falls. But even if the foreign output gap rises, foreign inflation may still fall as a result of the reduction in the home output gap reducing demand and marginal cost in the foreign economy.

Finally, we may compute the impact of the demand shock on the terms of trade for the home economy. We may derive the terms of trade response in the following way. From interest rate parity, it must be that (up to a first order), we have:

$$
r_{t}-E_{t} \pi_{H t+1}=r_{t}^{*}-E_{t} \pi_{F t+1}+E_{t}\left(\widehat{\tau}_{t+1}-\widehat{\tau}_{t}\right)
$$

Now, using the assumption on persistence of all variables, the fact that the steady state terms of trade in zero (in logs), and the Taylor rule, we may write the response of the current terms of trade as:

$$
\tau_{t}=-2 \frac{\gamma-\mu}{1-\mu} \pi_{t}^{R}
$$

Since $\pi_{t}^{R}$ is negative, the terms of trade must depreciate. Hence, when policy interest rates are above their zero lower bound, and policymakers follow a Taylor rule, a negative demand shock in one country is associated with a depreciation in that country's terms of trade, which cushions the impact of the shock on inflation and the output gap. 


\subsection{Demand Shocks in a liquidity trap}

Now assume that the demand shock satisfies $\varepsilon<\varepsilon_{H}(1)$. Then either one or both countries will be constrained by the zero lower bound on nominal interest rates. The affect of these shocks is obviously going to depend on the policy response, both the current and anticipated future responses. As stated above, we focus only on discretionary policy, assuming that the current policy-maker cannot credibly make announcements over future monetary policy actions. The next section examines the optimal policy response to a demand shock. But first, we explore the consequences of following the conventional policy, described as

$$
r_{t}=\max \left(0, \widetilde{r}_{t}\right), \quad r_{t}^{*}=\max \left(0, \widetilde{r}_{t}^{*}\right)
$$

Under this conjectured policy, each country will set its policy rate to target the natural interest rate, if this is feasible. Otherwise, policy interest rates will be zero. This is a natural extension of the optimal discretionary monetary rule in the closed economy literature on the 'zero bound' (e.g. Eggertson and Woodford 2003, Jung et al. 2005)³ .

The impact of the shock on home and foreign output gaps depends, for a given shock, on the actual value of $v$. We focus on two cases. In both cases, the home policy interest rate is zero, but the foreign policy rate is only zero for $v \leq v_{F}$. If $v>v_{F}$, then by rule (21), the foreign monetary authority will set $r_{t}^{*}=\widetilde{r}_{t}^{*}$.

Case 1. For $v \leq v_{F}$, we have

$$
\begin{aligned}
& \widehat{n}_{t}=(1-\beta \mu)\left[\frac{\widetilde{r}_{t}^{W}}{\Delta_{2}}+\frac{\widetilde{r}_{t}^{R}}{\Delta_{2}^{D}}\right] \\
& \widehat{n}_{t}^{*}=(1-\beta \mu)\left[\frac{\widetilde{r}_{t}^{W}}{\Delta_{2}}-\frac{\widetilde{r}_{t}^{R}}{\Delta_{2}^{D}}\right]
\end{aligned}
$$

where $\Delta_{2} \equiv s(1-\beta \mu)(1-\mu)-\mu k(\phi+s)>0$, and $\Delta_{2}^{D}=s_{D}(1-\beta \mu)(1-\mu)-\mu k\left(\phi+s_{D}\right)>0$, with $\Delta_{2}>\Delta_{2}^{D} \cdot 4$

In this case, the home output gap must fall, while the foreign output gap may rise or fall, depending on the size of $v$.

Case 2. For $v>v_{F}$, we have $\widetilde{r}_{t}^{W}=\widetilde{r}_{t}^{R}=\frac{\widetilde{r}_{t}}{2}$. Then we get:

\footnotetext{
${ }^{3}$ In order to implement (21), the authorities would need to follow an interest rate feedback rule which guarantees uniqueness of equilibrium. See, e.g. Gali (2009)

${ }^{4}$ These terms must be positive in order that the equilibrium be determinate. This puts a limit on the degree of persistence of the demand shock.
} 


$$
\begin{aligned}
& \widehat{n}_{t}=(1-\beta \mu) \widetilde{r}_{t}\left[\frac{1}{\Delta_{2}}+\frac{1}{\Delta_{2}^{D}}\right] \\
& \widehat{n}_{t}^{*}=(1-\beta \mu) \widetilde{r}_{t}\left[\frac{1}{\Delta_{2}}-\frac{1}{\Delta_{2}^{D}}\right]
\end{aligned}
$$

Again, the home output gap must fall. But in this case, the foreign output gap will always rise, because, from the definitions above, we have $\Delta_{2}>\Delta_{2}^{D}$.

It is straightforward to show that a negative demand shock causes the output gap in the home economy to fall by more when the economy is in a liquidity trap than under a Taylor rule. A fall in demand during a liquidity trap causes a persistent fall in inflation, which, given no adjustment in the nominal interest rate, causes a rise in the real interest rate, which causes a further fall in demand. So long as $\Delta_{2}>0$, this process converges when output falls by a sufficient amount.

In the open economy, however, there is a further effect at work. The fall in relative home country expected inflation leads to a rise in the home real interest rate, relative to the foreign real interest rate. In case 1 above, neither country's policy interest rate responds. By condition (19), this requires an anticipated terms of trade depreciation for the home country. Since the shock is temporary, an anticipated terms of trade depreciation can only be satisfied by an immediate terms of trade appreciation. Thus, the home country terms of trade must appreciate. The analogue of condition (20) under a liquidity trap in both countries is thus:

$$
\tau_{t}=2 \frac{\mu}{1-\mu} \pi_{t}^{R}
$$

Since in this case, $\pi_{t}^{R}<0$, the home country terms of trade appreciates. Thus, in a liquidity trap, relative prices move in the 'wrong direction', leading to a further fall in demand for home goods, following the initial negative demand shock. This appreciation helps to explain why the cross country spillover impact of a negative demand shock may be positive.

In case 2, the appreciation in the terms of trade of the home country is diminished by the increase in the foreign interest rate. The terms of trade response is described as:

$$
\tau_{t}=2 \frac{\mu}{1-\mu} \pi_{t}^{R}-\frac{\widetilde{r}_{t}^{*}}{1-\mu}
$$

The first term is again negative, but the second term is positive. In general, this can go in either direction. But in the quantitative analysis below, we see that, even in the case where the foreign central bank adjusts the policy rate when $\widetilde{r}_{t}^{*}>0$, the home terms of trade still 
appreciates.

\section{Optimal Monetary and Fiscal Policy}

We now turn to the analysis of the optimal policy response to a liquidity trap shock. We explore optimal cooperative monetary and fiscal policy responses. While a complete analysis of the determination of fiscal and monetary policy in a global liquidity trap would also require an exploration of the strategic interaction between non-cooperative policy authorities, this raises difficult technical issues (see Benigno and Benigno 2005), and so is left as a topic for future research. Focusing on the cooperative problem is a desirable first approach, since it sets out a benchmark for choosing a policy so as to maximize world welfare in response to a negative demand shock that undermines the normal mechanism of monetary policy ${ }^{5}$.

In order to analyze optimal policy, we first need to define an objective function. As shown in Cook and Devereux (2010a), a second order approximation to an equally weighted world social welfare can also be constructed in world averages and world differences.

$$
\begin{aligned}
V_{t}= & -\left(\widehat{n}_{t}^{R}\right)^{2} \cdot \frac{A}{2}-\left(\widehat{n}_{t}^{W}\right)^{2} \frac{B}{2}-\left(\widehat{c g}_{t}^{R}\right)^{2} \cdot \frac{F}{2}-\left(\widehat{c g}_{t}^{W}\right)^{2} \cdot \frac{H}{2}-J\left(\widehat{n}_{t}^{R}\right)\left(\widehat{c g}_{t}^{R}\right) \\
& -L\left(\widehat{n}_{t}^{W}\right)\left(\widehat{c g}_{t}^{W}\right)-\frac{\theta}{4 k}\left(\pi_{t}^{W}+\pi_{t}^{R}\right)^{2}-\frac{\theta}{4 k}\left(\pi_{t}^{W}-\pi_{t}^{R}\right)^{2}
\end{aligned}
$$

where

$$
\begin{aligned}
A & \equiv\left\{\frac{\left(1+\phi c_{y}\right)}{c_{y}^{2}}+\frac{(\sigma-D)}{D}\left(1+\frac{\left(1-c_{y}^{2}\right)}{c_{y}^{2} D}\right)\right\}=\frac{\left(s_{D D}+\phi\right)}{c_{y}} \\
s_{D D} & \equiv \frac{(D-1)\left(1-c_{y}^{2}\right)}{c_{y} D}+\frac{(\sigma)}{D}\left(\frac{1+c_{y}^{2}(D-1)}{c_{y} D}\right)<s_{D} \\
B & \equiv \frac{\left(\sigma+\phi c_{y}\right)}{c_{y}^{2}}=\frac{(s+\phi)}{c_{y}}, \\
H & \equiv \frac{1}{\left(1-c_{y}\right)} \frac{\sigma}{c_{y}^{2}}=\frac{1}{\left(1-c_{y}\right)} \frac{s}{c_{y}} L \equiv \frac{-\sigma}{c_{y}^{2}}=\frac{s}{c_{y}} \\
J & \equiv\left[-\frac{1}{c_{y}^{2}}-\frac{(\sigma-D)}{c_{y}^{2} D^{2}}\left(1+(v-1)(D-1) c_{y}^{2}\right)\right] \\
F & \equiv \frac{\left(\left(1-c_{y}\right)+c_{y} \sigma\right)}{\left(1-c_{y}\right) c_{y}^{2}}+\frac{(\sigma-D)}{c_{y}^{2} D^{2}}\left(1+(v-1)(D-1) c_{y}^{2}\right)
\end{aligned}
$$

\footnotetext{
${ }^{5}$ The cooperative approach to fiscal policy in a global liquidity trap is not necessarily unrealistic. In the immediate aftermath of the financial crash of 2008, the G20 group agreed on a joint policy response to the crisis which assigned target levels of fiscal stimulus to each member country.
} 
Thus, the social welfare function faced by the policy maker depends upon output gaps, inflation rates, fiscal gaps, and the interaction between these variables.

\subsection{Optimal Monetary Policy}

First, we focus on monetary policy alone. Assume that all fiscal gaps are zero, and the only policy instrument available is the policy interest rate in each country. Then the optimal cooperative policy problem under discretion is described by the Lagrangean:

$$
\begin{aligned}
& \max _{\widehat{n}_{t}^{R}, \widehat{n}_{t}^{W}, \pi_{t}^{W}, \pi_{t}^{R}, r_{t}, r_{t}^{*}} L_{t}=\quad V_{t}+\lambda_{1 t}\left[\pi_{t}^{W}-k(\phi+s) \widehat{n}_{t}^{W}-\beta E_{t} \pi_{t+1}^{W}\right] \\
& +\lambda_{2 t}\left[\pi_{t}^{R}-k\left(\phi+s_{D}\right) \widehat{n}_{t}^{R}-\beta E_{t} \pi_{t+1}^{R}\right] \\
& +\psi_{1 t}\left[s E_{t}\left(\widehat{n}_{t+1}^{W}-\widehat{n}_{t}^{W}\right)-E_{t}\left(\frac{r_{t}+r_{t}^{*}}{2}-\widetilde{r}_{t}^{W}-\pi_{t+1}^{W}\right)\right] \\
& +\psi_{2 t}\left[s_{D} E_{t}\left(\widehat{n}_{t+1}^{R}-\widehat{n}_{t}^{R}\right)-E_{t}\left(\frac{r_{t}-r_{t}^{*}}{2}-\frac{\widetilde{r}_{t}^{R}}{2}-\pi_{t+1}^{R}\right)\right] \\
& +\gamma_{1 t} r_{t}+\gamma_{2 t} r_{t}^{*}
\end{aligned}
$$

The first two constraints are the inflation equations in average and relative terms. The second two constraints are the average and relative 'IS' equations. The final two constraints are the non-negativity constraint on the two policy interest rates. The policy optimum involves the choice of the output gaps, the inflation rates and interest rates to maximize this Lagrangean. The first order conditions are:

$$
\begin{gathered}
-A \widehat{n}_{t}^{R}=\lambda_{2} k\left(\phi+s_{D}\right)+s_{D} \psi_{2} \\
-B \widehat{n}_{t}^{W}=\lambda_{1} k(\phi+s)+s \psi_{1} \\
k \lambda_{1}=\theta \pi_{t}^{W} \\
k \lambda_{2}=\theta \pi_{t}^{R} \\
\psi_{2 t}+\psi_{1 t}=\gamma_{1 t} \\
\psi_{1 t}-\psi_{2 t}=\gamma_{2 t}
\end{gathered}
$$

Together with the conditions (14)-(17), these equations determine the optimal policy solutions for the variables $n_{t}^{R}, n_{t}^{W}, \pi_{t}^{R}, \pi_{t}^{W}, r_{t}, r_{t}^{*}, \lambda_{1 t}, \lambda_{2 t}, \psi_{1 t}, \psi_{2 t}, \gamma_{1 t}$, and $\gamma_{2 t}$. Combining (25) and (26) with (23) and (24), we obtain the relationship between world and relative output gaps, inflation rates, and the multipliers $\psi_{2 t}$ and $\psi_{1 t}$. Since the underlying demand shock is 
either a constant (negative) number, or zero, the solution for all variables during the period of the shock will be time invariant. Hence we can drop the time notation. Thus:

$$
\begin{gathered}
-A \widehat{n}^{R}=\theta \pi^{R}\left(\phi+s_{D}\right)+s_{D} \psi_{2} \\
-B \widehat{n}^{W}=\theta \pi^{W}(\phi+s)+s \psi_{1}
\end{gathered}
$$

Then, solving the conditions (14)-(17) using the fact that the shock to the natural real interest rates will revert to zero with probability $1-\mu$ per period, we have:

$$
\begin{gathered}
\pi^{R}(1-\beta \mu)=k\left(\phi+s_{D}\right) \widehat{n}^{R} \\
s_{D}(\mu-1) \widehat{n}^{R}=\frac{r-r^{*}}{2}-\widetilde{r}^{R}-\mu \pi^{R} \\
\pi^{W}(1-\beta \mu)=k(\phi+s) \widehat{n}^{W} \\
s(\mu-1) \widehat{n}^{W}=\frac{r+r^{*}}{2}-\widetilde{r}^{W}-\mu \pi^{W}
\end{gathered}
$$

From (31) and (32), we can derive the partial solution for the relative output gap as:

$$
\Delta_{2}^{D} \widehat{n}^{R}=-\left(\frac{r-r^{*}}{2}-\widetilde{r}^{R}\right)(1-\beta \mu)
$$

Likewise, the world output gap that solves (33) and (34) is

$$
\Delta_{2} \widehat{n}^{W}=-\left(\frac{r+r^{*}}{2}-\widetilde{r}^{W}\right)(1-\beta \mu)
$$

Now using (31) in (23) we get:

$$
-\left[A(1-\beta \mu)+\theta k\left(\phi+s_{D}\right)^{2}\right] \widehat{n}_{t}^{R} \equiv-\Psi_{D} \widehat{n}_{t}^{R}=s_{D} \psi_{2}(1-\beta \mu)
$$

and (33) in (24) we get

$$
-\left[B(1-\beta \mu)+\theta k(\phi+s)^{2}\right] \widehat{n}_{t}^{W} \equiv-\Psi \widehat{n}_{t}^{W}=s \psi_{1}(1-\beta \mu)
$$

Using (35) and (37), and rearranging, we arrive at:

$$
\Omega_{D}\left(\frac{r_{t}-r_{t}^{*}}{2}-\widetilde{r}_{t}^{R}\right)=\psi_{2}
$$

and using (36) and (38), and rearranging, we arrive at: 


$$
\Omega\left(\frac{r_{t}+r_{t}^{*}}{2}-\widetilde{r}_{t}^{W}\right)=\psi_{1}
$$

where $\Omega_{D} \equiv \frac{\Psi_{D}}{\Delta_{2}^{D} s_{D}}$ and $\Omega \equiv \frac{\Psi}{\Delta_{2} s}$. By the properties already defined above, it must be that $\Omega_{D} \geq \Omega$, with strict inequality when $v<2$.

From (39) and (40), we can now characterize the jointly optimal monetary policy in terms of the properties of the policy interest rates $r_{t}$ and $r_{t}^{*}$. The key question is to see the conditions under which either the home, the foreign, or both non-negativity conditions on interest rates are binding; i.e. what determines when the zero lower bound is reached for each country? Note that since $\varepsilon<\varepsilon_{H}(v)$, it must be that $r=\widetilde{r}(\varepsilon, v)<0$, so clearly the unconstrained optimal policy is not a feasible solution.

\subsection{Characteristics of the optimal policy}

We now discuss the characteristics of the optimal policy problem. The critical information may be obtained from conditions (39) and (40), in conjunction with the characteristics of the natural real interest rates (10) and (11).

From (27), the home policy interest rate is zero whenever $\psi_{1}+\psi_{2}>0$ and from (28) the foreign rate is zero when $\psi_{1}-\psi_{2}>0$. In the case $v=1, \widetilde{r}_{t}^{R}=0$, and $\widetilde{r}_{t}^{W}<0$. Setting $r_{t}=r_{t}^{*}=0$ in (39) and (40), we find that $\psi_{1}>0$ and $\psi_{2}=0$, so that both constraints are binding. Thus $r_{t}=r_{t}^{*}=0$ is a solution when $v=1$.

In the more general case, we can establish the following proposition.

Proposition 1 For $\varepsilon<\varepsilon_{H}(1)$, the optimal policy is characterized by the conditions; a) $r_{t}=0$, b) there exists a critical value $\bar{v}$, such that (i) for $1 \leq v \leq \bar{v}, r_{t}^{*}=0$, (ii), for $v>\bar{v}$, $r_{t}^{*}$ satisfies:

$$
r_{t}^{*}=\widetilde{r}^{*}\left(\varepsilon_{t}, v\right)-\frac{\left(\Omega_{D}-\Omega\right)}{\Omega_{D}+\Omega} \widetilde{r}\left(\varepsilon_{t}, v\right)>0,
$$

with $r_{t}^{*}>\widetilde{r}^{*}\left(\varepsilon_{t}, v\right)$, and $\bar{v}<v_{F}$.

Proof. To prove the proposition, initially assume that a) holds, so that $r_{t}=0$. Then from (39) and (40), we may write

$$
\gamma_{2}=\psi_{1}-\psi_{2}=\Omega\left(\frac{r^{*}}{2}-\widetilde{r}_{t}^{W}(\varepsilon, v)\right)+\Omega_{D}\left(\frac{r^{*}}{2}+\widetilde{r}_{t}^{R}(\varepsilon, v)\right)
$$

Define the right hand side of $(41)$ as $J(\varepsilon, v)$. If $J(\varepsilon, v)>0$, then $r^{*}=0$ must hold. Assuming this is the case, we have 


$$
J(\varepsilon, v)=-\Omega \widetilde{r}_{t}^{W}(\varepsilon, v)+\Omega_{D} \widetilde{r}_{t}^{R}(\varepsilon, v)
$$

By the definition of $\widetilde{r}_{t}^{W}(\varepsilon, v)$ and $\widetilde{r}_{t}^{R}(\varepsilon, \bar{v})$, it must be that $\widetilde{r}_{t}^{R}(\varepsilon, 1)=0$, so that $J(\varepsilon, 1)=$ $-\Omega \widetilde{r}_{t}^{W}(\varepsilon, 1)>0$, while $\widetilde{r}_{t}^{W}(\varepsilon, 2)>\widetilde{r}_{t}^{R}(\varepsilon, 2)$, so that $J(\varepsilon, 2)=-\Omega \widetilde{r}_{t}^{W}(\varepsilon, 2)+\Omega_{D} \widetilde{r}_{t}^{R}(\varepsilon, 2)<0$, since from the definitions above, we know that $\Omega=\Omega_{D}$ when $v=2$. Hence, by continuity, there exists a value $\bar{v}$ defined by the condition $J(\varepsilon, \bar{v})=-\Omega \widetilde{r}_{t}^{W}(\varepsilon, \bar{v})+\Omega_{D} \widetilde{r}_{t}^{R}(\varepsilon, \bar{v})=0 .{ }^{6}$

Taking $v$ such that $1 \leq v \leq \bar{v}$, and setting $r_{t}=r_{t}^{*}=0$ in (39) and (40) implies that $J(\varepsilon, v)>0$, which confirms the conjecture that both zero bound constraints are strictly binding, so both policy rates are zero. At $v=\bar{v}, J(\varepsilon, \bar{v})=0$, and the home constraint is strictly binding while for foreign constraint is just binding. For $\bar{v}<v \leq 2, J(\varepsilon, v)<0$. Then the home country constraint is binding, but the foreign constraint is not binding. Then for $v \geq \bar{v}$, given that the foreign constraint is not binding, we set $\gamma_{2 t}=0$ in (28), which implies that $\psi_{1}=\psi_{2}$. Using this condition, we set $r_{t}=0$ in (39) and (40), and solve for the equilibrium foreign country interest rate as

$$
r_{t}^{*}=\widetilde{r}^{*}(\varepsilon, v)-\frac{\left(\Omega_{D}-\Omega\right)}{\Omega_{D}+\Omega} \widetilde{r}(\varepsilon, v)>0
$$

Note that for $v \geq \bar{v}$, this is strictly positive, since from the definition of $J(\varepsilon, v)$, we have $r_{t}^{*}=-\frac{2}{\Omega_{D}+\Omega} J(\varepsilon, v)>0$, for $v \geq \bar{v}$.

Moreover, the critical value $\bar{v}$ must satisfy $\bar{v}<v_{F}$. This is because, given the definition of the natural interest rates, it must be that $\widetilde{r}_{t}^{W}\left(\varepsilon, v_{F}\right)=\frac{\widetilde{r}_{t}\left(\varepsilon, v_{F}\right)}{2}$, and $\widetilde{r}_{t}^{R}\left(\varepsilon, v_{F}\right)=\frac{\widetilde{r}_{t}\left(\varepsilon, v_{F}\right)}{2}$. Hence $J\left(\varepsilon, v_{F}\right)=-\left(\Omega-\Omega_{D}\right) \frac{\widetilde{r}_{t}\left(\varepsilon, v_{F}\right)}{2}<0$, since $\Omega_{D}>\Omega$. Therefore, the foreign policy rate is strictly positive, for $v \geq \bar{v}$, even in the range $\left[\bar{v}, v_{F}\right]$, for which the foreign natural real interest rate is strictly negative.

This establishes part b) of the proposition. To show that part a) holds, assume that $r_{t}=0$. Then for $v \leq \bar{v}$,

$$
\gamma_{1}=\psi_{1}+\psi_{2}=-\Omega \widetilde{r}_{t}^{W}(\varepsilon, v)-\Omega_{D} \widetilde{r}_{t}^{R}(\varepsilon, v)>0
$$

\footnotetext{
${ }^{6}$ We have not shown that $\bar{v}$ is unique. However, in extensive simulation over different parameter settings, we did not find any instances of non-uniqueness.
} 
so that $r_{t}=0$ is confirmed. For $\bar{v}<v \leq 2$, using (43), we have

$$
\begin{aligned}
\gamma_{1}=\psi_{1}+\psi_{2} & =-\Omega \frac{\left(\widetilde{r}_{t}(\varepsilon, v)+\widetilde{r}_{t}^{*}(\varepsilon, v)\right)}{2}-\Omega_{D} \frac{\left(\widetilde{r}_{t}(\varepsilon, v)-\widetilde{r}_{t}^{*}(\varepsilon, v)\right)}{2}+\left(\Omega-\Omega_{D}\right) \frac{r_{t}^{*}}{2} \\
& =-\left(\Omega+\Omega_{D}\right) \frac{\widetilde{r}_{t}(\varepsilon, v)}{2}-\left(\Omega-\Omega_{D}\right) \frac{\widetilde{r}_{t}^{*}(\varepsilon, v)}{2}+\left(\Omega-\Omega_{D}\right)\left(\frac{\widetilde{r}_{t}^{*}(\varepsilon, v)}{2}-\frac{\left(\Omega_{D}-\Omega\right)}{\left(\Omega_{D}+\Omega\right)} \widetilde{r}(\varepsilon, v)\right) \\
& =-2 \frac{\Omega \Omega_{D}}{\left(\Omega_{D}+\Omega\right)} \widetilde{r}_{t}(\varepsilon, v)>0
\end{aligned}
$$

where the second line equality follows from use of (43), and the third line follows by cancellation and rearrangement. Hence, $r_{t}=0$ is satisfied for $\bar{v}<v \leq 2$.

This proposition makes it clear that the sense in which the two countries are in a liquidity trap is critically determined not by the fact that their respective natural real interest rates are negative, but by the strength of the shock and the size of the trade flows between the countries. Figure 2 illustrates the behaviour of the foreign interest rate for various values of $v$. For a shock that would be large enough to drive the world natural real interest rate below zero in the fully open world economy (i.e. $\varepsilon<\varepsilon_{H}(1)$ ), the foreign country will also set the interest rate at the zero bound, if it is sufficiently open to trade with the home country $(v \leq \bar{v})$. But no matter how big is the shock, there is always a $\bar{v}$ such that, for $v \geq \bar{v}$, the foreign country will keep its policy interest rate above zero, and also above its natural interest rate. And there is always an interval $\left[\bar{v} v_{F}\right]$ for which the foreign policy rate is above zero, even though its natural interest rate below zero.

A similar logic holds for different values of the demand shock, for a given $v>1$. This leads to a trade-off between the size of home bias and the size of the shock in the assessement of whether a liquidity trap in one country spills over into another country. Figure 3 illustrates this. The Figure illustrates a downward sloping locus of points in $v-\varepsilon$ space. Above and to the right of the locus, the foreign country sets a positive policy rate higher than the foreign natural real interest rate. Below and to the left of the locus, the foreign country is constrained by the zero lower bound. Note that the locus become steeper has $v$ increases, because the foreign country is less and less sensitive to foreign demand shocks, the higher is $v$. Literally, as $v$ approaches 2 , the required negative home demand shock that would put the foreign country into a liquidity trap becomes infinitely large.

The key intuition behind the optimal monetary policy rule comes from the benefits of tempering the home country terms of trade appreciation that occurs in a global liquidity trap. As we discussed above, when $v>1$, the home terms of trade exacerbates the negative demand effects of the liquidity shock on the home country, drawing world demand away from home goods rather than cushioning the impact of the fall in demand. The only way 
in which the home monetary authority could limit this is to reduce its interest rate; but of course at the zero bound, it cannot engage in any further interest rate reduction. But the foreign country can limit the home terms of trade appreciation by increasing its own interest rate. For higher and higher values of $v$, this is of direct benefit to the foreign country, since in those circumstances, it is more likely that the movement in the terms of trade causes an expansion in the foreign output gap. We can write the home terms of trade as follows;

$$
\tau_{t}=2 \frac{\mu}{1-\mu}\left(\frac{k\left(\phi+s_{D}\right)}{\Delta_{2}^{D}}\left(\widetilde{r}_{t}^{W}+\frac{r_{t}^{*}}{2}\right)+\frac{r_{t}^{*}}{(1-\mu)}\right.
$$

For $1 \leq v<\bar{v}$, then $\tau_{t}<0$, and the terms of trade appreciates. But as $\bar{v} \leq v \leq 2$, the appreciation is mitigated by a rise in the foreign policy rate.

The following proposition gives some more insight into the nature of the optimal monetary policy. We may show that by setting a positive policy rate, the foreign central bank is importing deflation.

Proposition 2 If the foreign central bank follows an optimal $r_{t}^{*}>0$, then the home output gap will be negative and both home and foreign inflation will be negative.

Proof. If $\gamma_{2}=0$

$$
\psi_{1}=\psi_{2} \equiv \psi
$$

Multiply both sides of (37) by $D$ to equalize the right side with the right side of $(38)$

$$
D \Psi_{D} \widehat{n}_{t}^{R}=\Psi \widehat{n}_{t}^{W}
$$

Add (35) and (36) and premultiply by $D \Psi_{D}$ to get

$$
D \Psi_{D} \Delta_{2} \widehat{n}_{t}^{W}+\Delta_{2}^{D} D \Psi_{D} \widehat{n}_{t}^{R}=(1-\beta \mu) D \Psi_{D} \widetilde{r}_{t}
$$

Insert the optimal monetary condition

$$
\left[D \Psi_{D}+\Delta_{2}^{D} \Psi\right] \widehat{n}_{t}^{W}=(1-\beta \mu) D \Psi_{D} \widetilde{r}_{t}
$$

So $\widehat{n}_{t}^{W}<0$. From (44) we have $\widehat{n}_{t}^{R}<0$ so $\widehat{n}_{t}<0$. From (33) and (31) we have $\pi_{t}^{W}<0$ and $\pi_{t}^{R}<0$, so $\pi_{t}<0$. Insert (33) and (31) into (44):

$$
\left[(1-\beta \mu) B+\theta k(\phi+s)^{2}\right] \frac{(1-\beta \mu)}{k(\phi+s)} \pi_{t}^{W}=D\left[(1-\beta \mu) A+\theta k\left(\phi+s_{D}\right)^{2}\right] \frac{(1-\beta \mu)}{k\left(\phi+s_{D}\right)} \pi_{t}^{R}
$$

Cancel $\frac{(1-\beta \mu)}{k}$ and $B=\frac{(\phi+s)}{c_{y}}$ so the leftand side is 


$$
\frac{\left[\frac{(1-\beta \mu)}{c_{y}}(\phi+s)+\theta k(\phi+s)^{2}\right]}{(\phi+s)} \pi_{t}^{W}=\left[\frac{(1-\beta \mu)}{c_{y}}+\theta k(\phi+s)\right] \pi_{t}^{W}
$$

Multiply both sides by $\left(\phi+s_{D}\right)$

$$
\left[\frac{(1-\beta \mu)}{c_{y}}\left(\phi+s_{D}\right)+\theta k(\phi+s)\left(\phi+s_{D}\right)\right] \pi_{t}^{W}=D\left[\frac{(1-\beta \mu)}{c_{y}}\left(\phi+s_{D D}\right)+\theta k\left(\phi+s_{D}\right)^{2}\right] \pi_{t}^{R}
$$

Define

$$
\begin{aligned}
& \Pi_{1} \equiv\left[\frac{(1-\beta \mu)}{c_{y}}\left(\phi+s_{D}\right)+\theta k(\phi+s)\left(\phi+s_{D}\right)\right] \\
& \Pi_{2} \equiv D\left[\frac{(1-\beta \mu)}{c_{y}}\left(\phi+s_{D}\right)+\theta k\left(\phi+s_{D}\right)^{2}\right]
\end{aligned}
$$

so

$$
\Pi_{1} \pi_{t}^{W}=\Pi_{2} \pi_{t}^{R}
$$

Calculate

$$
\begin{aligned}
\Pi_{2}-\Pi_{1} & = \\
\frac{(1-\beta \mu)}{c_{y}}(D-1) \phi+\frac{(1-\beta \mu)}{c_{y}}\left(D s_{D D}-s_{D}\right)+\theta k\left(\phi+s_{D}\right)\left[D\left(\phi+s_{D}\right)-(\phi+s)\right] & = \\
\frac{(1-\beta \mu)}{c_{y}}(D-1) \phi+\frac{(1-\beta \mu)}{c_{y}}\left(D s_{D D}-s_{D}\right)+\theta k\left(\phi+s_{D}\right)\left[(D-1) \phi+\left(D s_{D}-s\right)\right] & = \\
\frac{(1-\beta \mu)}{c_{y}}(D-1) \phi+\frac{(1-\beta \mu)}{c_{y}}\left(D s_{D D}-s_{D}\right)+\theta k\left(\phi+s_{D}\right)[(D-1) \phi] & >0
\end{aligned}
$$

Hence, the fall in inflation of the home country is less than the world average decline. Therefore inflation must also fall in the foreign country.

We may also ask what would happen if the foreign central bank followed the non-optimal rule (21), setting its policy rate equal to the foreign natural real interest rate. In that case, we find that the foreign country would experience inflation and a positive output gap.

Proposition 3 If the foreign central bank, non-optimally, closes the interest gap, $r_{t}^{*}=\widetilde{r}_{t}^{*}$, there would be a contraction and deflation in the home economy, $\widehat{n}_{t}<0, \pi_{H t}<0$ and result in expansion and inflation in the foreign economy $\widehat{n}_{t}^{*}>0, \pi_{F t}>0$.

Proof. Note that $r_{t}=0 . \frac{r_{t}^{*}}{2}=\frac{\widetilde{r}_{t}^{*}}{2}$, so $r_{t}^{W}-\widetilde{r}_{t}^{W}=r_{t}^{R}-\widetilde{r}_{t}^{R}=\frac{\widetilde{r}_{t}}{2}<0$. Write (35) and (36)

$$
\Delta_{2} \widehat{n}_{t}^{W}=\Delta_{2}^{D} \widehat{n}_{t}^{R}=(1-\beta \mu) \frac{\widetilde{r}_{t}}{2}<0
$$


Since $\Delta_{2}>\Delta_{2}^{D}>0, \widehat{n}_{t}^{R}<\widehat{n}_{t}^{W}<0$. Since the average level of output drops by less than the relative level, $\widehat{n}_{t}<0$ and $\widehat{n}_{t}^{*}>0$. Add both sides of (33) and (31)

$$
(1-\beta \mu) \pi_{t}=k(\phi+s) \widehat{n}_{t}^{W}+k\left(\phi+s_{D}\right) \widehat{n}_{t}^{R}<0
$$

Since both $\widehat{n}_{t}^{R}, \widehat{n}_{t}^{W}<0, \pi_{t}<0$. Subtract (31) from (33) Subtract the world Phillips curve

$$
(1-\beta \mu) \pi_{t}^{*}=k(\phi+s) \widehat{n}_{t}^{W}-k\left(\phi+s_{D}\right) \widehat{n}_{t}^{R}
$$

Multiply both sides of the equation by $\Delta_{2}^{D} \Delta_{2}$. We can write $\Delta_{2}^{D} \Delta_{2} \widehat{n}_{t}^{W}=\Delta_{2}^{D}(1-\beta \mu) \frac{r_{t}}{2}$ $\operatorname{and} \Delta_{2}^{D} \Delta_{2} \widehat{n}_{t}^{R}=\Delta_{2}(1-\beta \mu) \frac{r_{t}}{2}$

$$
\begin{aligned}
\Delta_{2}^{D} \Delta_{2}(1-\beta \mu) \pi_{t}^{*} & =k(\phi+s) \Delta_{2}^{D} \Delta_{2} \widehat{n}_{t}^{W}-k\left(\phi+s_{D}\right) \Delta_{2}^{D} \Delta_{2} \widehat{n}_{t}^{R} \\
& =\left[\phi\left(\Delta_{2}^{D}-\Delta_{2}\right)+\left(s \Delta_{2}^{D}-s_{D} \Delta_{2}\right)\right] k(1-\beta \mu) \frac{\widetilde{r}_{t}}{2}
\end{aligned}
$$

Note $\left(s \Delta_{2}^{D}-s_{D} \Delta_{2}\right)=\left(s_{D}-s\right) \mu \phi k$, so

$$
\Delta_{3}^{D} \Delta_{3}(1-\beta \mu) \pi_{t}^{*}=(1-\beta \mu) k \phi\left[\left(\Delta_{2}^{D}-\Delta_{2}\right)+\left(s_{D}-s\right) \mu k\right] \frac{\widetilde{r}_{t}}{2}>0
$$

Since $\left(\Delta_{2}^{D}-\Delta_{2}\right)<0$ and $\left(s_{D}-s\right)<0$

\subsection{Optimal Monetary and Fiscal Policy}

We now extend the analysis to encompass the joint determination of monetary and fiscal policy together. Since active fiscal policy involves having non-zero fiscal 'gaps' it is useful first to state some basic results concerning the impact of fiscal spending policies in this model. From Cook and Devereux, (2011), we can establish the following:

Proposition 4 In a liquidity trap in both countries, a) the domestic fiscal multiplier is greater than unity, b) the cross country fiscal multiplier is negative, and c) a fiscal expansion generates a terms of trade deterioration.

Proof. See Cook and Devereux (2011)

The logic behind the proposition is that a persistent fiscal expansion will raise expected inflation in the domestic economy, which, with a fixed nominal interest rate, will tend to reduce the real interest rate, and crowd in domestic consumption, thus generating a multiplier in excess of unity. But by the same token, the fall in the nominal interest rate must be 
accompanied by an expected terms of trade appreciation, which necessitates immediate depreciation. In the same way that the terms of trade appreciate following a fall in demand, in a liquidity trap, they depreciate following a fiscal expansion. But this depreciation generates a fall in demand in the rest of the world, so the cross country multiplier is negative.

With these results, we go on to compute the jointly optimal fiscal and monetary policy response to the demand shock. Again, the cooperative optimal policy response to a liquidity trap involves maximizing (22) in each period, taking expectations of all future variables as given, subject to the inflation equations for world averages and differences, given by (14) and (16), and subject to the non-negativity constraints on nominal interest rates in each country. Since from the results of the previous section we know that the non-negatively constraint on the home country policy rate will always bind for the duration of the shock, we only impose the non-negativity condition on the foreign interest rate.

Given this, we have the Lagrangean expression:

$$
\begin{aligned}
\max _{\widehat{n}_{t}^{R}, \widehat{n}_{t}^{W}, c g_{t}^{R}, c g_{t}^{W}, \pi_{t}^{W}, \pi_{t}^{R}, r_{t}^{*}} L_{t}= & -\left(\widehat{n}_{t}^{R}\right)^{2} \cdot \frac{A}{2}-\left(\widehat{n}_{t}^{W}\right)^{2} \frac{B}{2}-\left(\widehat{c}_{t}^{R}\right)^{2} \cdot \frac{F}{2}-\left(\widehat{c g}_{t}^{W}\right)^{2} \cdot \frac{H}{2} \\
& -J\left(\widehat{n}_{t}^{R}\right)\left(\widehat{c g}_{t}^{R}\right)-L\left(\widehat{n}_{t}^{W}\right)\left(\widehat{c g}_{t}^{W}\right)-\frac{\theta}{4 k}\left(\pi_{t}^{W}+\pi_{t}^{R}\right)^{2}-\frac{\theta}{4 k}\left(\pi_{t}^{W}-\pi_{t}^{R}\right)^{2} \\
& +\lambda_{1 t}\left[\pi_{t}^{W}-k(\phi+s) \widehat{n}_{t}^{W}+k s \cdot \widehat{c g}{ }_{t}^{W}-\beta E_{t} \pi_{t+1}^{W}\right] \\
& +\lambda_{2 t}\left[\pi_{t}^{R}-k\left(\phi+s_{D}\right) \widehat{n}_{t}^{R}+k s_{D} \widehat{c g}_{t}^{R}-\beta E_{t} \pi_{t+1}^{R}\right] \\
& +\psi_{1 t}\left[s E_{t}\left(\widehat{n}_{t+1}^{W}-\widehat{n}_{t}^{W}\right)-s E_{t}\left(\widehat{c g}_{t+1}^{W}-\widehat{c g}_{t}^{W}\right)-E_{t}\left(\frac{r_{t}^{*}}{2}-\widehat{r}_{t}^{W}-\pi_{t+1}^{W}\right)\right] \\
& +\psi_{2 t}\left[s_{D} E_{t}\left(\widehat{n}_{t+1}^{R}-\widehat{n}_{t}^{R}\right)-s_{D} E_{t}\left(\widehat{c g}_{t+1}^{R}-\widehat{c g}_{t}^{R}\right)-E_{t}\left(-\frac{r_{t}^{*}}{2}-\frac{\widetilde{r}_{t}^{R}}{2}-\pi_{t+1}^{R}\right)\right] \\
& +\gamma_{t}\left[r_{t}^{*}\right]
\end{aligned}
$$

The first two constraints are the inflation equations in average and relative terms. The second two constraints are the average and relative 'IS' equations. The final constraint is the non-negativity constraint on the foreign policy interest rate. The policy optimum involves the choice of the output gaps, the government spending 'gaps', the inflation rates and the foreign interest rate to maximize this Lagrangean. The first order conditions of the maximization are:

$$
\begin{gathered}
-A \widehat{n}_{t}^{R}-J\left(\widehat{c g}_{t}^{R}\right)=\lambda_{2} k\left(\phi+s_{D}\right)+s_{D} \psi_{2} \\
-B \widehat{n}_{t}^{W}-L\left(\widehat{c g}_{t}^{W}\right)=\lambda_{1} k(\phi+s)+s \psi_{1}
\end{gathered}
$$




$$
\begin{gathered}
F \widehat{c g}_{t}^{R}+J\left(\widehat{n}_{t}^{R}\right)=k s_{D} \lambda_{2}+s_{D} \psi_{2} \\
H \widehat{c g}_{t}^{W}+L\left(\widehat{n}_{t}^{W}\right)=k s \lambda_{1}+s \psi_{1} \\
k \lambda_{1}=\theta \pi_{t}^{W} \\
k \lambda_{2}=\theta \pi_{t}^{R} \\
\psi_{2 t}-\psi_{1 t}+\gamma_{t}=0
\end{gathered}
$$

These equations, in conjunction with (14)-(17), give the conditions determining average and relative output gaps, inflation rates, fiscal gaps, Lagrange multipliers, and the value of either $\gamma$ or $r_{t}^{*}$. As in the previous subsection, we can reduce these equation into a condition which determines whether the foreign country's policy rate is positive or constrained by the zero bound. But now this is simultaneously determined with the size of the average and relative fiscal gaps. First, take (48), (50) and (51). Combine these with (14) and (15) to get the relationship between the world average fiscal gap and the interest rate gap as follows:

$$
\left[\left(\Delta_{2} H L+\Delta_{3} B L\right)+\phi f(1-\mu) s\right] \widehat{c g}_{t}^{W}=[f(\phi+s)+(1-\beta \mu) B L]\left(\frac{r_{t}^{*}}{2}-\widetilde{r}_{t}^{W}\right)
$$

where $\Delta_{3}=\Delta_{2}+k \phi>0, H L \equiv H+L>0, B L \equiv B+L>0$ and $f \equiv \phi \theta k>0$. Since $r_{t}^{*} \geq 0$, from this, it is clear that when the world average natural rate falls below zero, the world average fiscal gap must increase.

Note that, outside a liquidity trap, it would never be desirable to have a non-zero fiscal gap. But when at least one of the the policy rates is constrained by the zero lower bound, the world output gap is negative, and inflation is negative. Then fiscal spending, by creating anticipated inflation, can reduce real interest rates, stimulate private demand, and reduce the current world output gap.

We may use a similar procedure to compute the relationship between the relative fiscal gap and the relative interest rate gap. This gives us the condition:

$$
\left[\Delta_{2}^{D} F J+\Delta_{3}^{D} J A+f \phi s_{D}(1-\mu)\right] \widehat{c g}_{t}^{R}=-\left[f\left(\phi+s_{D}\right)+(1-\beta \mu) J A\right]\left(\frac{r_{t}^{*}}{2}+\widetilde{r}_{t}^{R}\right)
$$

where $\Delta_{3}^{D}=\Delta_{2}^{D}+k \phi>0, F J \equiv F+J>0$, and $J A \equiv J+A>0$.

Note when $v=1$, given that $\varepsilon<\varepsilon(1)$, it must be that both countries are constrained by the zero bound. In addition, it must be that $\widetilde{r}_{t}^{R}=0$. Therefore, both countries must have identical and positive fiscal gaps. 
More generally, for the case $v \geq 1$, since $r_{t}^{*} \geq 0$ and $\widetilde{r}_{t}^{R} \leq 0$, the expression (55) cannot immediately be signed. But it is shown below that $r_{t}^{*}-\widetilde{r}_{t}^{*} \leq \widetilde{r}_{t}$. Hence the relative fiscal gap is always non-negative. It follows then that the home country fiscal gap will always be positive.

Finally, we may use (53), (48), (47), (51), (52), in conjunction with (14) and (17) to compute a solution for $\gamma$ as:

$$
\gamma=\psi_{1}-\psi_{2}=\Gamma\left(\frac{r_{t}^{*}}{2}-\widetilde{r}_{t}^{W}\right)-\Gamma_{D}\left(\frac{r_{t}^{*}}{2}+\widetilde{r}_{t}^{R}\right)
$$

where $\Gamma(v)$ and $\Gamma_{D}(v)$ satisfy the condition that $\Gamma_{D}(v) \geq \Gamma(v)$, with $\Gamma_{D}(2)=\Gamma(2)^{7}$

Equation (56) satisfies the same properties as (41) in the previous subsection. In particular, when $v=1$, then $r_{t}^{*}=0, \widetilde{r}_{t}^{R}=0$, and so $\gamma>0$, ensuring that the foreign zero bound constraint is binding. In that case, it can immediately be seen from (54) and (55) that the home and foreign fiscal gaps are equal, and positive. Alternatively, in the case $v=2$, then (56) gives the solution $r_{t}^{*}=\widetilde{r}_{t}^{*}$ and then $\gamma=0$, so the zero bound constraint is binding. In this case the home fiscal gaps are positive, and the foreign fiscal gaps are zero.

As before, there is a critical value for $v$, denoted $\bar{v}$, such that for $v \geq \bar{v}$, then $r_{t}^{*}>0$. In this case, since $\gamma=0$, we may derive the optimal value of $r_{t}^{*}$ from (56) itself. In summary, we may then define the behavior of the foreign policy interest rate in the same way as before. Thus:

$$
\begin{aligned}
& \text { For } 1 \leq v \leq \bar{v}, \quad r_{t}^{*}=0 \\
& \text { For } \bar{v}<v<2, \quad r_{t}^{*}=\widetilde{r}_{t}^{*}(\varepsilon, v)-\frac{\left(\Gamma_{D}-\Gamma\right)}{\left(\Gamma_{D}+\Gamma\right)} \widetilde{r}_{t}(\varepsilon, v)
\end{aligned}
$$

With the condition that $\Gamma_{D} \geq \Gamma$, this ensures that $r_{t}^{*}-\widetilde{r}_{t}^{*} \leq \widetilde{r}_{t}$, as stated above. Thus, the characteristics of monetary policy are similar to those of the last section. The difference is that now monetary policy response on the part of the foreign country is augmented by positive fiscal gaps on the part of one or both governments. Note also that the stance of monetary policy will affect the optimal fiscal gaps chosen by each country. Only when there is substantial trade openness, so that $v \leq \bar{v}$, and $r_{t}^{*}=0$, will monetary policy play no role in an optimal policy. More generally, there is an interaction between the optimal fiscal and monetary responses to a liquidity trap in one country. The way in which this takes place is

\footnotetext{
${ }^{7}$ The expressions are defined as follows: $\Gamma_{D} \equiv \Omega_{D}+\frac{\left(J \Delta_{2}^{D}+A \Delta_{3}^{D}\right)(1-\beta \mu)+\left(\phi+s_{D}\right) \theta k \phi s_{D}(1-\mu)}{\Delta_{3}^{D} s_{D}} g^{R}, \quad \Gamma \equiv \Omega+$ $\frac{\left(L \Delta_{2}+B \Delta_{3}\right)(1-\beta \mu)+(\phi+s) \theta k \phi s(1-\mu)}{\Delta_{3} s} g^{W}, g^{R}=-\frac{\left[f\left(\phi+s_{D}\right)+(1-\beta \mu) J A\right]}{\left[\Delta_{2}^{D} F J+\Delta_{3}^{D} J A+f \phi s_{D}(1-\mu)\right]}$, and $g^{W}=\frac{[f(\phi+s)+(1-\beta \mu) B L]}{\left.\left[\Delta_{2} H L+\Delta_{3} B L\right)+\phi f(1-\mu) s\right]}$.
} 
explored in the following section.

\section{Numerical Analysis of Optimal Policy}

We now provide a numerical illustration of the jointly optimal cooperative monetary fiscal policy. To evaluate the economy quantitatively, we adopt some parameters from Cook and Devereux (2010a). Let $\beta=0.99$, so each period is a quarter, and this translates to a value of the steady state interest rate $\bar{r}=0.01$. The Frisch labor supply elasticity is set at $\phi=1$. Price stickiness is $\kappa=0.85$, so that $k=0.027$, as in Christiano et al. (2009). Let the share of government in output be 20 percent, so that $c_{y}=0.8$. We assume the inverse of the intertemporal demand elasticity $\sigma$, is equal to 2 . The persistence of the demand shock is set at $0.8(\mu=0.8)$ implying an expected length of the slump to be 5 quarters. We set the elasticity of substitution between individual good varieties within a country, $\theta$, equal to 5 . Finally, we set the preference shock in the home country $\varepsilon$ so that at $v=1$ (the case without any home bias), the natural real interest rate at the quarterly frequency would fall from 1 percent to -1.7 percent, with persistence $\mu$.

Figure 4 illustrates the response of home and foreign output gaps, home and foreign government spending gaps, home and foreign inflation, the foreign country optimal policy rate, as well as the foreign natural real interest rate, and the home country terms of trade, for different values of $v$, when the optimal fiscal and monetary policy response is chosen. The Figure takes account of condition (57), so that, at each value of $v$, the non-negativity constraint on $r_{t}^{*}$ is tested, and if it is not binding, the optimal foreign policy rate is chosen to satisfy (57). The first thing to note is that at $v=1$, then clearly the zero bound is binding in both countries, and all variables respond in the same way in the two countries. The output gap falls by over 7 percent in both countries, and this is coupled with a fall in the rate of inflation by equal amounts. Since both countries are affected equally, and interest rates are zero, adjusting the fiscal gaps is the only possible policy response to the shock. The Figure shows a a positive response of the fiscal gap in each country. Thus, fiscal policy should behave counter-cyclically, and equally so in each country for a world without home bias in preferences.

Now, as $v$ rises above unity, we know that the impact of the shock on the foreign natural interest rate becomes muted, while the opposite occurs for the home natural interest rate. The negative response of the foreign output gap is then reduced, while that of the home output gap is increased. As $v$ rises more and more, holding the foreign policy rate constant, 
the foreign output gap may actually increase. This is due to the sharp terms of trade appreciation of the home country, leading to an expenditure switching towards foreign output. A similar dynamic occurs in the response of the inflation rates in the two countries - home inflation becomes more and more negative as $v$ rises, while the negative response of foreign inflation becomes less and less. The optimal response of fiscal policy gaps is illustrated in panel $\mathrm{b}$ of the Figure. As $v$ rises, home fiscal policy becomes more aggressive, while the foreign fiscal policy becomes more muted.

Panel d illustrates the optimal response of the foreign country policy rate, alongside the foreign country natural real interest rate. Note that at $v=1$, the foreign policy rate is stuck at zero, while the natural real interest rate is at -0.017 . As $v$ rises, the response of the foreign natural interest rate becomes less and less, as is obvious from the formula (57). Eventually, as $v$ rises to 2, the foreign country would be entirely unaffected by the shock, and the foreign natural interest rate would rise to 0.01 , the steady state natural interest rate. But the key feature of panel $d$ is that the foreign country will raise its policy rate above zero for values of $\widetilde{r}_{t}^{*}<0$. That is, the foreign country will choose positive interest rates after point $\bar{v}$ as part of an optimal cooperative policy package, even though, by the usual closed economy logic, it should be still in a liquidity trap, since its natural rate of interest is below zero. Equivalently, the foreign country will not follow a policy of offsetting the movement in the foreign natural interest rate to the greatest extent that it can, so long as the policy rate is above the zero bound. Rather, it chooses to raise policy rates, even though $\widetilde{r}_{t}^{*}<0$. In fact, panel d makes clear that, above $\bar{v}$, the foreign country will always set its policy rate above the steady state natural rate of interest. Thus, by any definition of the term, the optimal monetary stance for the foreign country, in face of the home liquidity trap, is to tighten its monetary policy.

So an optimal cooperative policy response to a liquidity trap can be characterized by expansionary fiscal policy in all countries, but contractionary monetary policy in the least affected country. This seemingly paradoxical result is related to the results of section (4) above. As $v$ rises, the home economy is significantly more affected by the negative demand shock. An optimal policy response is to raise world demand, and to re-orient world demand towards the home country. Raising world demand is accomplished by expansionary fiscal policy, and particularly so in the country which is the source of the demand shock. But reorientation of demand towards the source country is achieved by tighter monetary policy in the least affected country. The raising of the foreign policy rate is associated with an appreciation of the foreign currency, which generates an additional expenditure switching of demand towards the home country. Since the impact of the home country shock on foreign 
output is positive in any case, when $v$ is sufficiently greater than unity, the rise in the foreign policy rate has the additional benefit that it helps to minimize the response of the foreign output gap to the home country shock. The Figure shows that the tightening of the policy rate in the foreign country as $v$ rises reduces the degree to which the home terms of trade appreciates in response to the initial savings shock.

We note that, when an optimal foreign monetary policy is used, the foreign country has a very small fiscal gap. While it is optimal for the foreign country to follow an expansionary fiscal policy. But quantitatively, the size of the fiscal expansion is much less than that of the home country.

Figure 5 provides further illustration of the key interaction between monetary and fiscal policy in responding to the liquidity trap in the home country. The Figure contrasts the optimal policy for fiscal and monetary policy to that where fiscal policy is set optimally, but monetary policy is set according to the conventional rule (21). Thus, the foreign country sets the policy rate equal to zero when the natural real interest rate is negative, and equal to the natural real interest rate when it is above zero. The Figure shows that the response of fiscal policy under this alternative (non-optimal) monetary rule is substantially different when $v>1$. The key feature of this policy is that it is excessively expansionary for the foreign economy, relative to the optimal rule. As $v$ rises more and more, the foreign economy experiences a boom, which is countered by a contractionary fiscal policy. At the same time, the outcome of expansionary monetary and contractionary fiscal policy in the foreign country leads to an excessive contraction in the home economy, which then requires a much greater fiscal expansion than would take place under the optimal policy. This comparison makes clear that the optimal foreign monetary policy adjustment in effect reduces the extent to which the home country has to engage in expansionary fiscal policy in response to the liquidity trap. It does so precisely by tempering the sharp terms of trade appreciation of

the home economy. Note from panel e that under the non-optimal monetary rule (21), the terms of trade appreciates much more for the home economy that it would under the optimal policy. In addition, under this non-optimal rule, the foreign economy experiences inflation, while the deflation in the home economy is substantially greater than it would be under the optimal policy.

\section{Conclusions}

The experience of major recessions in many of the worlds largest economic regions, together with low or zero interest rates, has reduced confidence in the ability of monetary policy to 
respond to economic shocks, and suggests that only fiscal policy can be used as a countercyclical device. This paper shows that in a world economy where countries are affected in different ways by 'liquidity trap' shocks, monetary and fiscal policy may be used in mutually supportive ways, and in some cases the standard prescriptions for monetary policy response to a liquidity trap may fail to apply. A relatively tight monetary policy in the least hit country facilitates an efficient redirection of world spending, and reduces the extent to which fiscal expansion must be used to raise world expenditure. The key useful feature of monetary policy in our model is that it tempers the perverse response of real exchange rates to shocks that occurs in a liquidity trap. The underlying message of the paper is that in a liquidity trap, the exchange rate response may exacerbate rather than ameliorate the impact of negative demand shocks.

\section{References}

[1] Auerbach, Alan, and Maurice Obstfeld (2006) "The Role for Open Market Operations in a Liquidity Trap", American Economic Review.

[2] Beetsma Roel and Henrik Jensen, (2005), "Monetary and Fiscal Policy Interactions in a Micro-Founded Model of a Monetary Union", Journal of International Economics, 67, 320-352.

[3] Benhabib, Jess, Stephanie Schmitt Grohe, and Martin Uribe, (2002) "Avoiding Liquidity Traps", Journal of Political Economy.

[4] Benigno, Gianluca and Pierpaolo Benigno (2006), "Designing Targeting Rules for International Monetary Policy Cooperation", Journal of Monetary Economics, 53, 473-506.

[5] Blanchard, Olivier and Roberto Perotti, (2002), "An Empirical Characterization of the Dynamic Effects of changes in Government Spending and Taxes on Output", Quarterly Journal of Economics, 117, 1329-1368.

[6] Bodenstein, Martin, Christopher J. Erceg, and Luca Guerrieri (2009) "The Effect of Foreign Shocks When Interest Rates are at Zero" IFdp 983, Board of Governors of the Federal Reserve System.

[7] Christiano, Larry, Martin Eichenbaum, and Sergio Rebelo, (2009) "When is the Government Spending Multiplier Large?", Northwestern University. 
[8] Cook, David, and Michael B. Devereux, (2011) "Optimal Fiscal Policy in a World Liquidity Trap", European Economic Review, forthcoming.

[9] Cook, David and Michael B. Devereux (2010) "Global vs Local Liquidity Traps", mimeo

[10] Cogan, John, Tobias Cwik, John Taylor, and Volker Wieland, (2009) "New Keynesian Versus Old Keynesian Government Spending Multipliers", mimeo

[11] Davig, Troy and Eric M. Leeper (2009) "Monetary Fiscal Interactions and Fiscal Stimulus", NBER d.p. 15133.

[12] Devereux, Michael B. (2010) "Fiscal Deficits, Debt, and Monetary Policy in a Liquidity Trap", Central Bank of Chile, Working Paper 581.

[13] Engel, Charles (2010), "Currency Misalignments and Optimal Monetary Policy: A Reinvestigation", mimeo

[14] Eggerston, Gauti, (2010) "What Fiscal Policy is Effective at Zero Interest Rates?", NBER Macroeconomics Annual, forthcoming.

[15] Eggertson Gauti and Michael Woodford, (2003) "The Zero Interest Bound and Optimal Monetary Policy", Brookings Papers on Economic Activity.

[16] Eggertsson, Gauti and Michael Woodford, (2005) "Optimal Monetary and Fiscal Policy in a Liquidity Trap", ISOM Annual.

[17] Faia, Ester and Tommaso Monacelli, (2008) "Optimal Monetary Policy in a Small Open Economy with Home Bias," Journal of Money, Credit and Banking, 40, 721-750.

[18] Fujiwara, Ippei, Nao Sudo, and Yuki Teranishi, (2009) "The Zero Lower Bound and Monetary Policy in a Global Economy: A Simple Analytical Investigation", International Journal of Central Banking.

[19] Fujiwara, Ippei, Tomoyuki Nakajimaz, Nao Sudox, and Yuki Teranishi, (2010) "Global Liquidity Trap", mimeo, Bank of Japan

[20] Fujiwara, Ippei, and Kozu Ueda (2010) "The Fiscal Multiplier and Spillover in a Global Liquidity Trap", IMES d.p. 2010-E-3. Bank of Japan.

[21] Jeanne, Olivier (2009) "The Global Liquidity Trap", mimeo

[22] Krugman, Paul, (1998), "It's baaack: Japan's Slump and the Return of the Liquidity Trap", Brookings Papers on Economic Activity", 2, 137-87. 
[23] Jung, Taehun, Yuki Terinishi, and Tsutomo Watanabe, (2005) "The Zero Bound on Nominal Interest Rates and Optimal Monetary Policy", Journal of Money Credit and Banking.

[24] Monacelli, Tomasso and Roberto Perotti, (2008), "Fiscal Policy, Wealth Effects and Markups", NBER d.p. 14584.

[25] Perotti, Roberto, (2007) "In Search of the Transmission Mechanism of Fiscal Policy", NBER 13143.

[26] Rotemberg, J. and M. Woodford (1998) "An Optimization Based Econometric Framework for the Evaluation of Monetary Policy", NBER Technical Working Paper 233.

[27] Svensson, Lars E. (2003) "Escaping from a Liquidity Trap and Deflation: The Foolproof Way and Others" Journal of Economic Perspectives 17, 145-166.

[28] Woodford, Michael (2003) Interest and Prices, MIT Press

[29] Woodford, Michael (2010) "Simple Analytics of the Government Expenditure Multiplier", mimeo, Columbia University. 


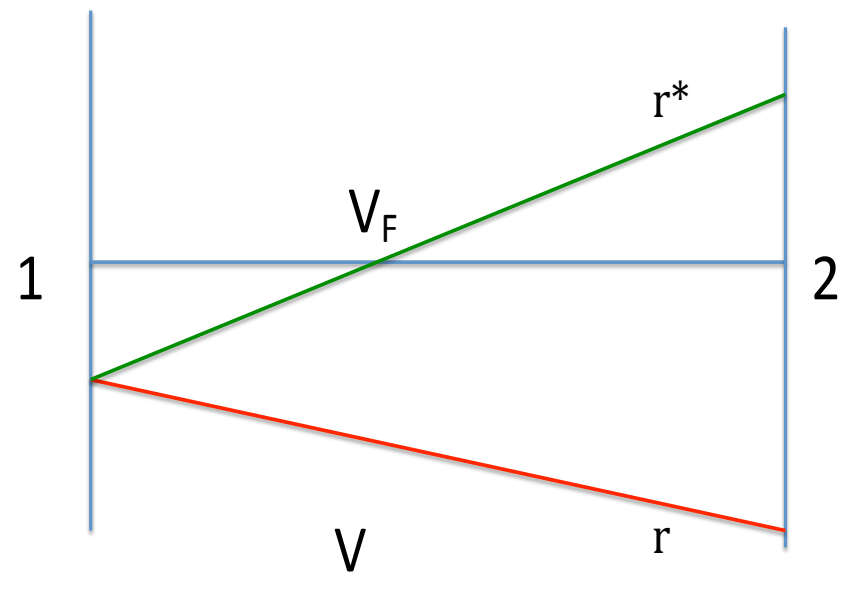

Figure 1 


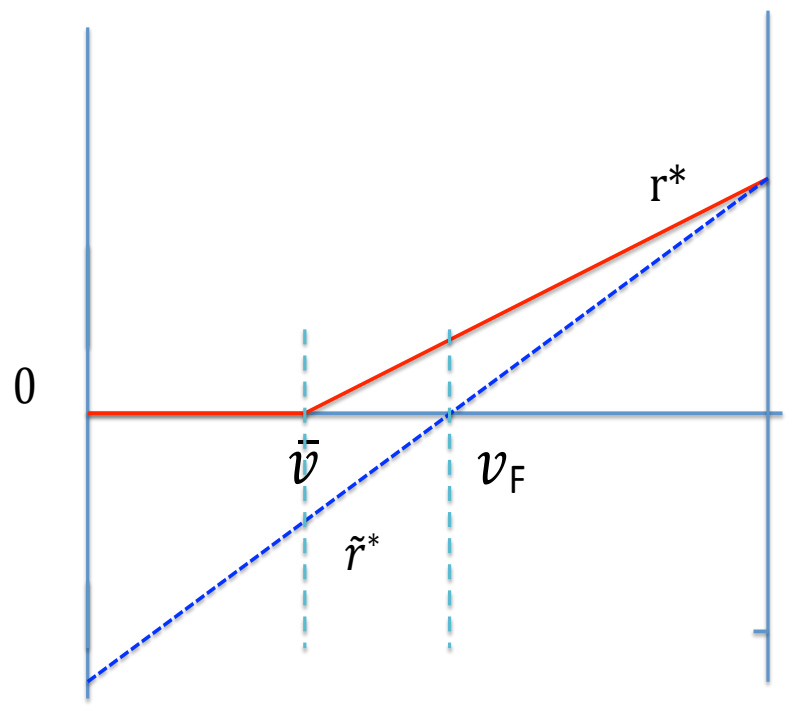

Figure 2 


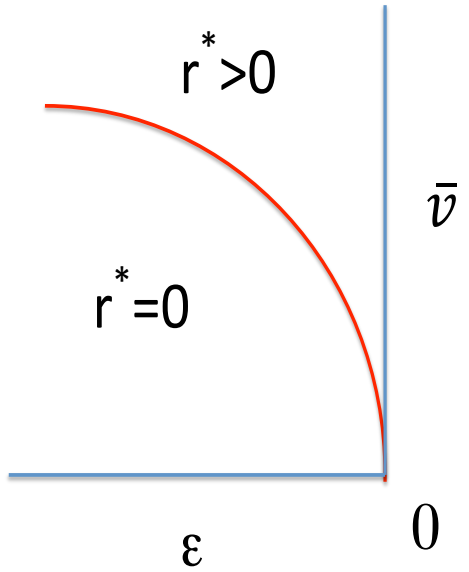

Figure 3 
Figure 4: Optimal Policy

(a) Output Gaps

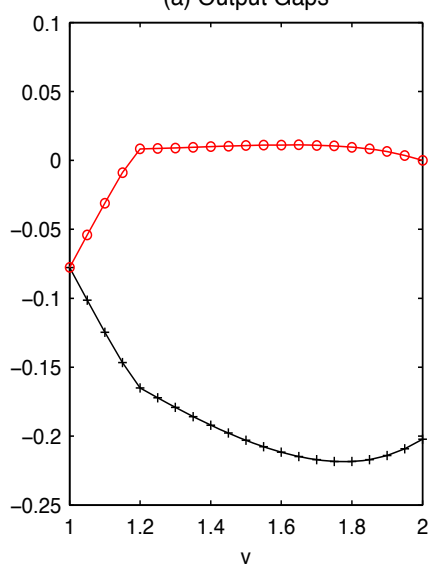

(c) Inflation

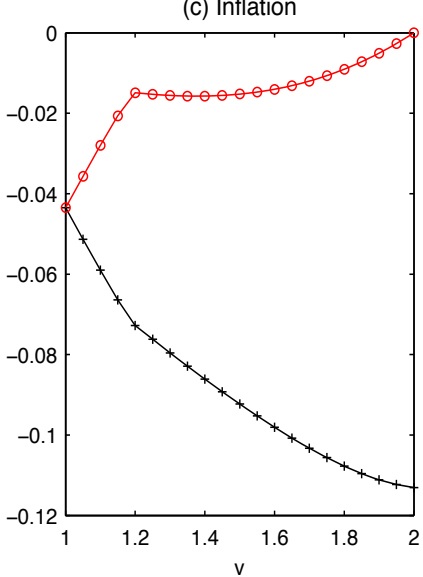

(e) Terms of Trade

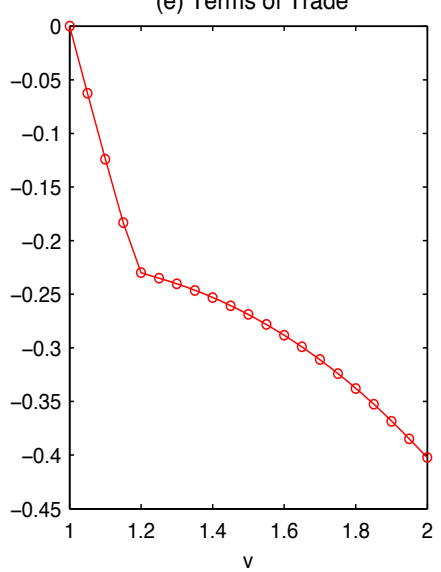

(b) Fiscal Gaps
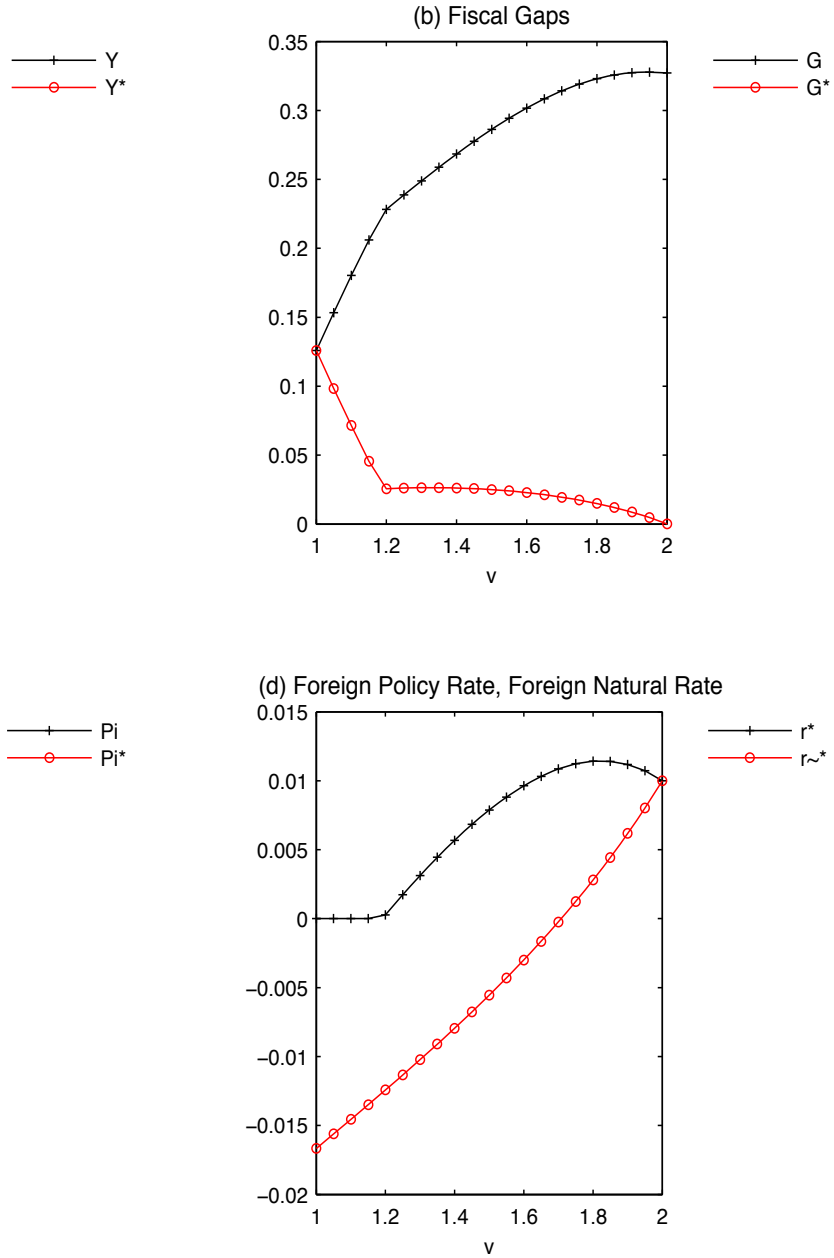
Figure 5: Optimal and Constrained Policy

(a) Output Gaps

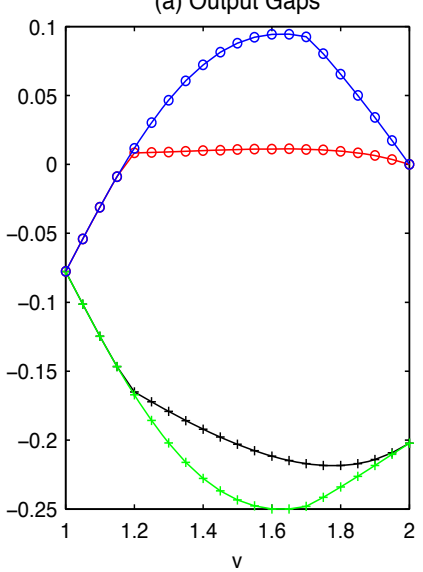

(c) Inflation

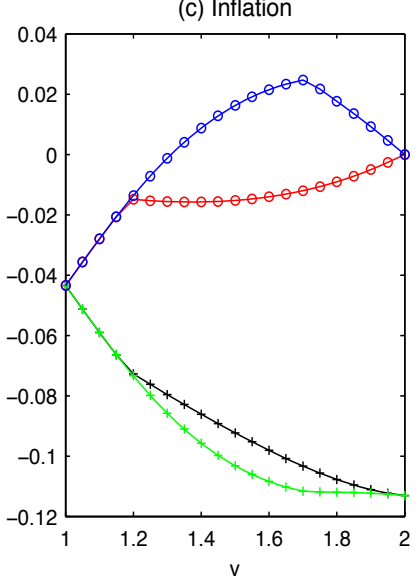

(e) Terms of Trade

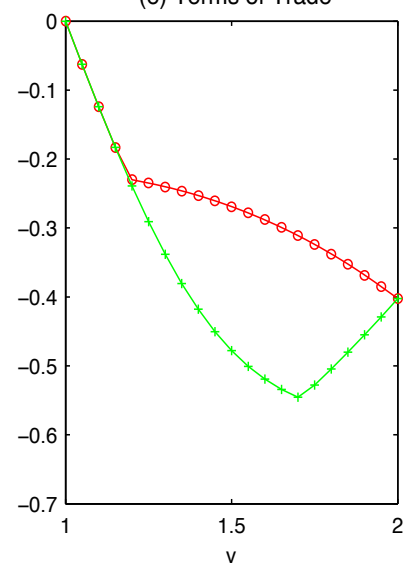

(b) Fiscal Gaps
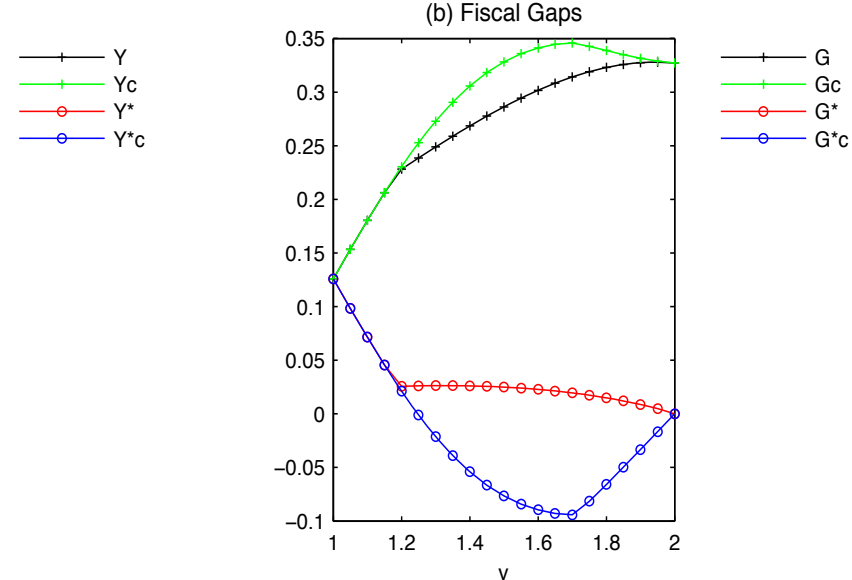

(d) Foreign Policy Rate, Foreign Natural Rate

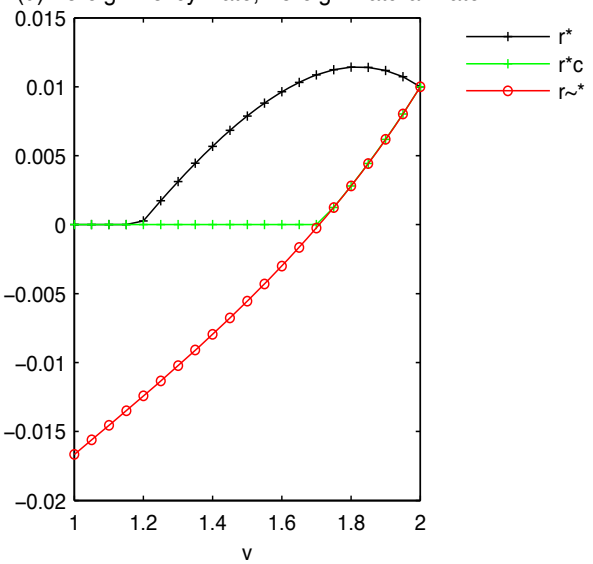

